BRIAN LUKOFF, PH.D.

APRIL 14, 2015

BUT EVERYTHING MADE SENSE IN CLASS! 


\title{
But everything made sense in class!
}

\section{The exam was nothing like the}

\author{
homework!
}

The test wasn't an accurate reflection of my true knowledge! 
Three problems 


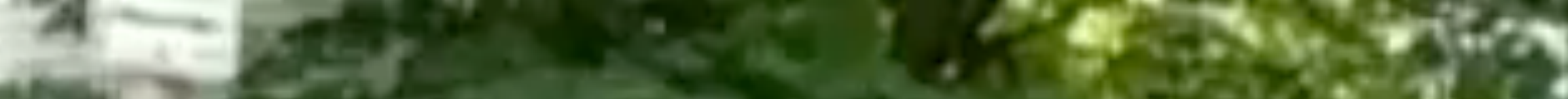

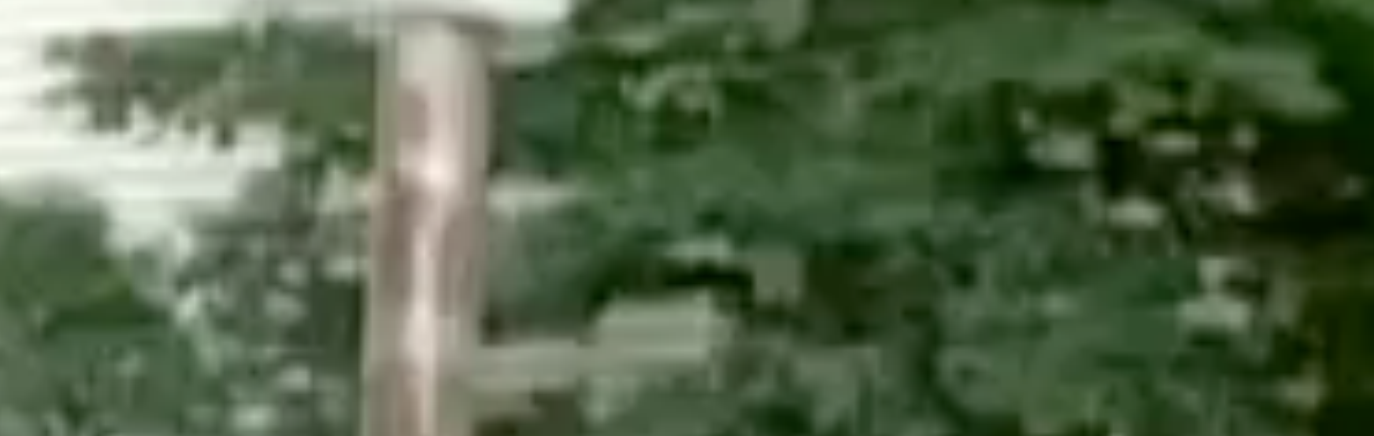

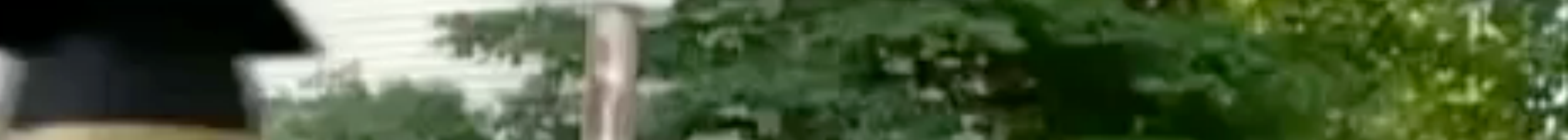

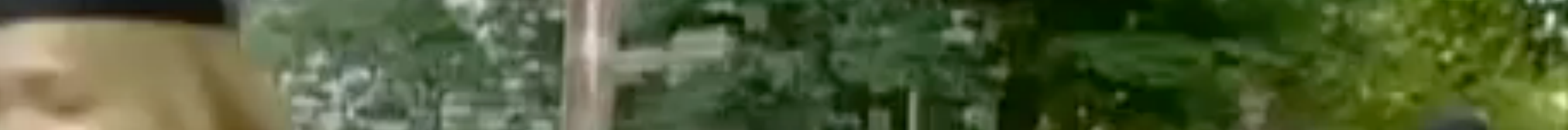
tifing
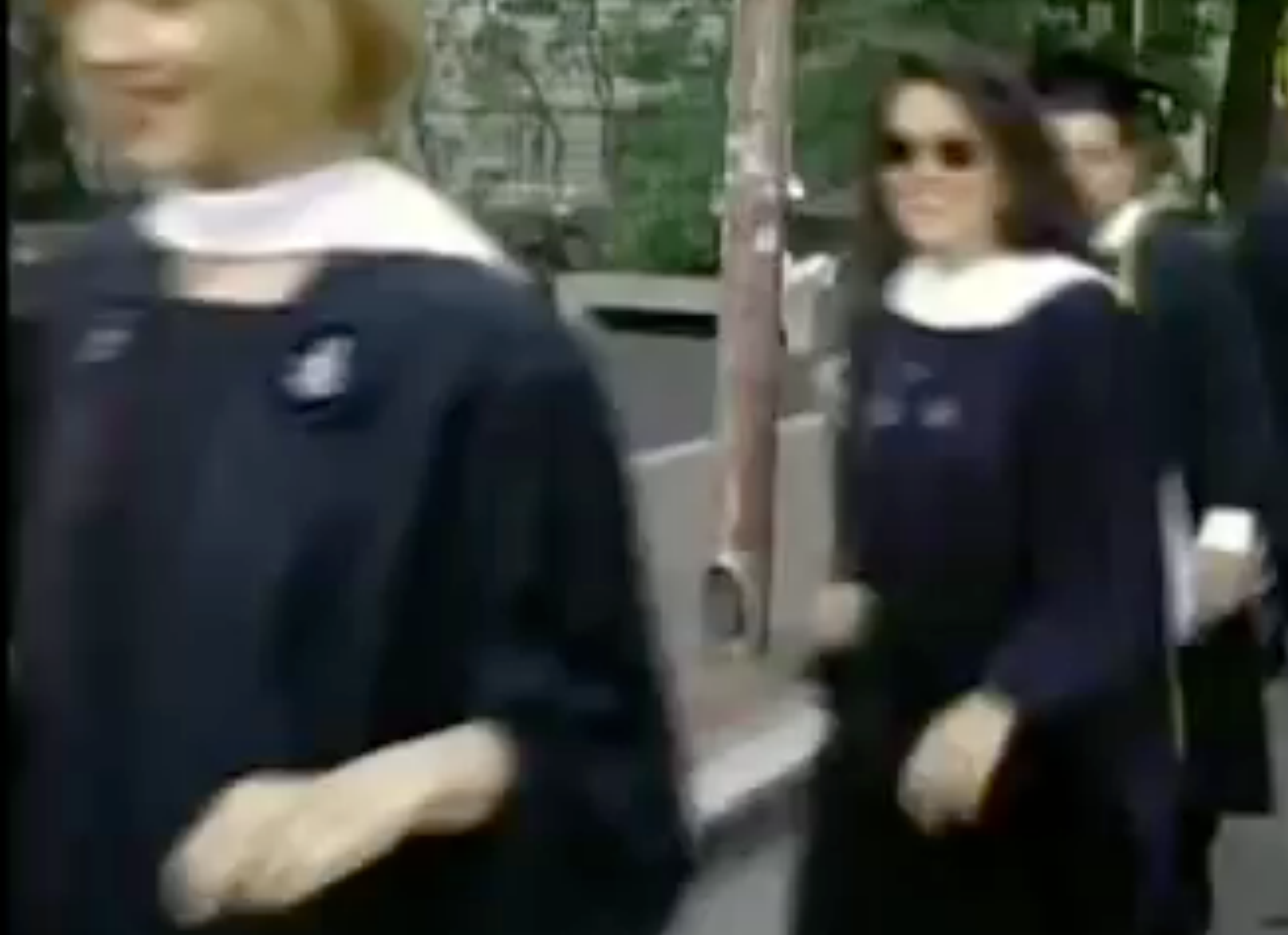

$+1$

(1)

(4)
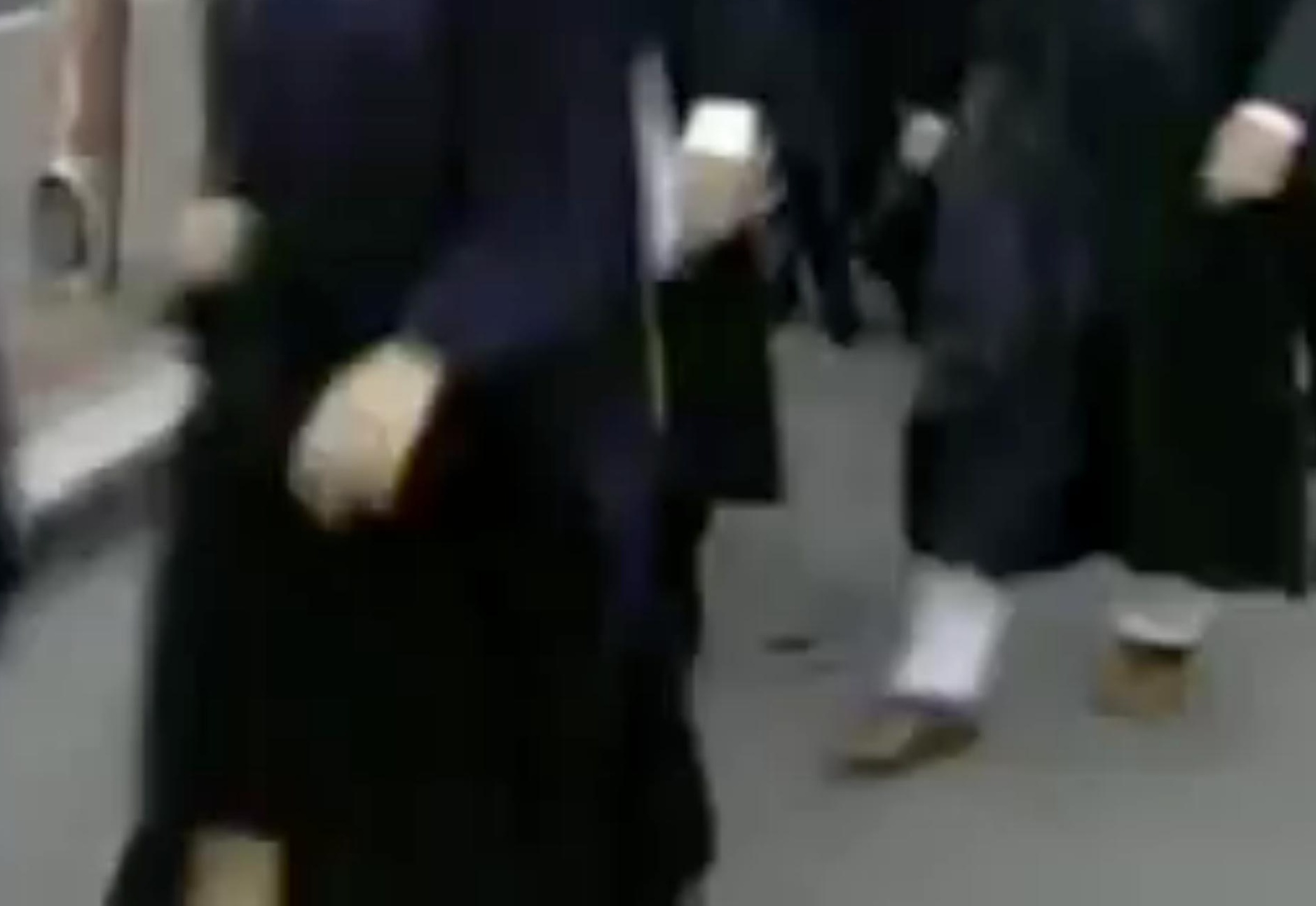

1

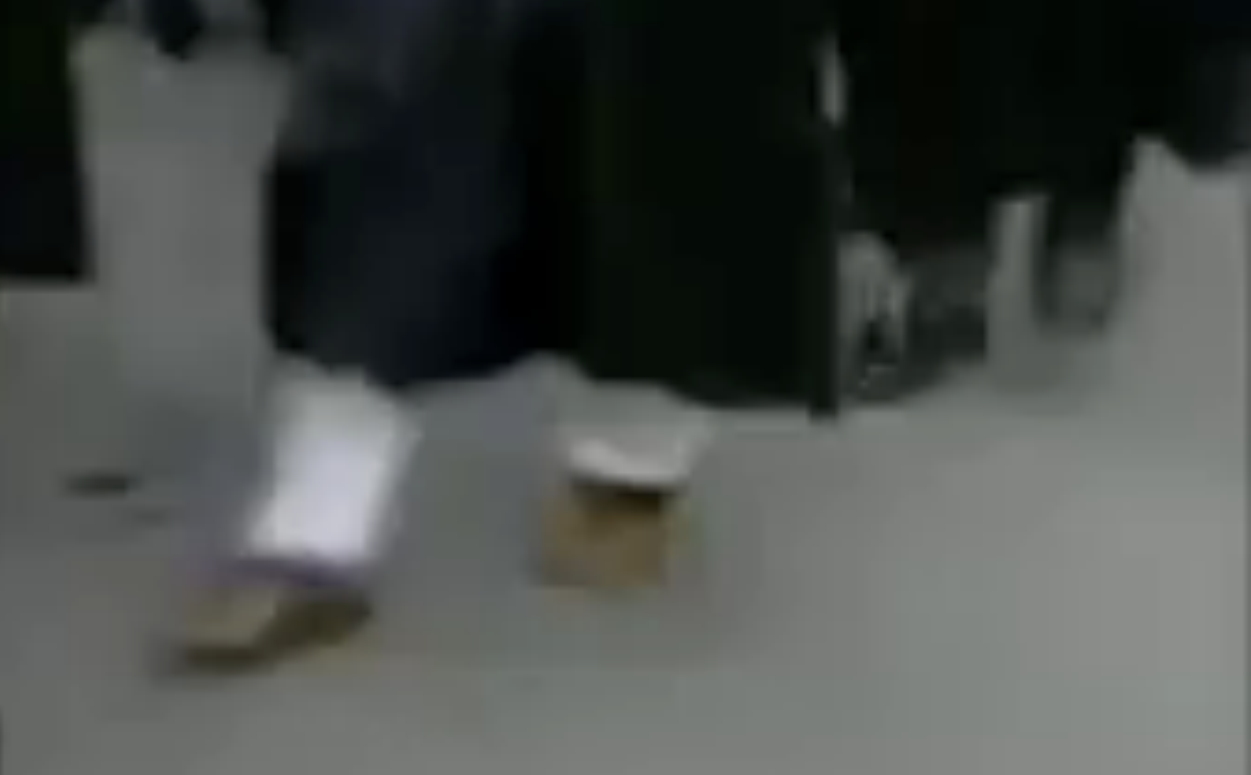




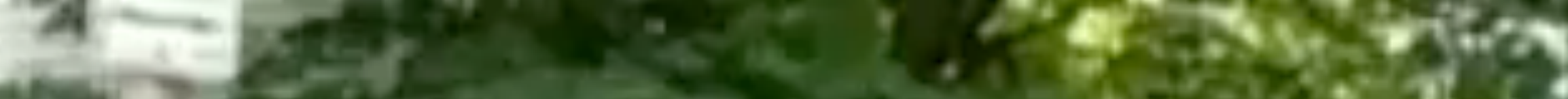

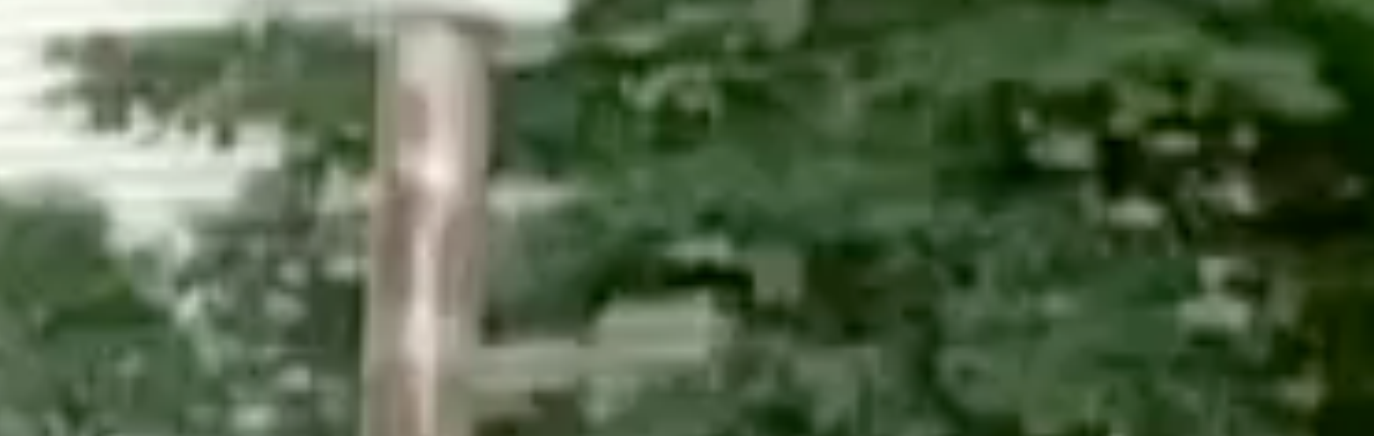

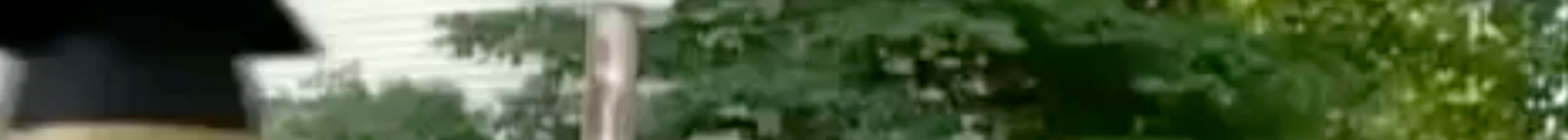

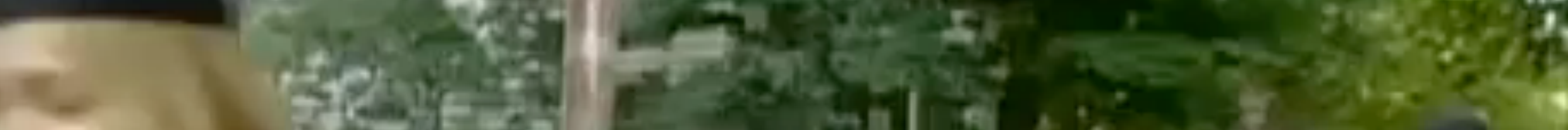
tifing
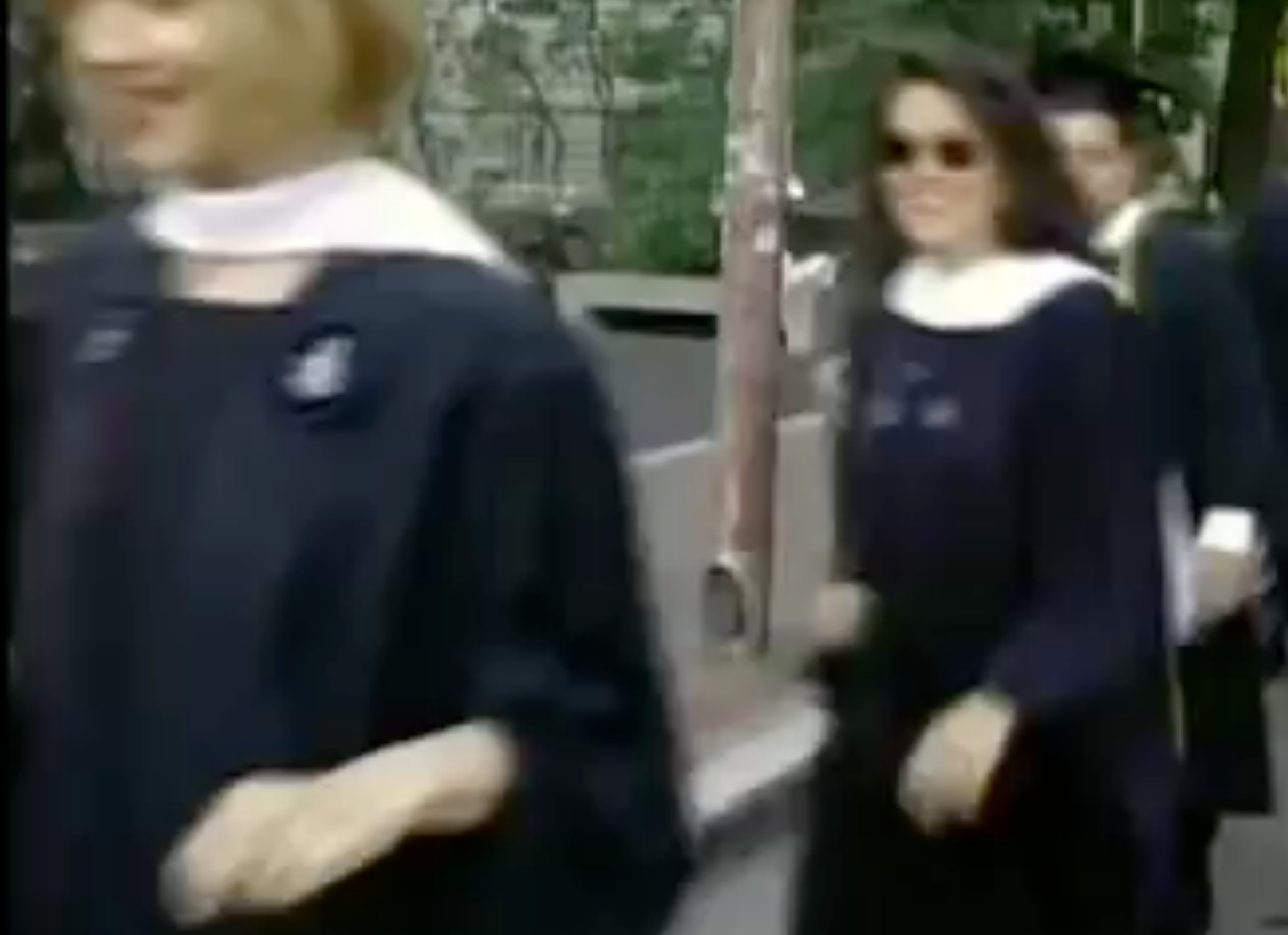

$+1$

(1)

(4)
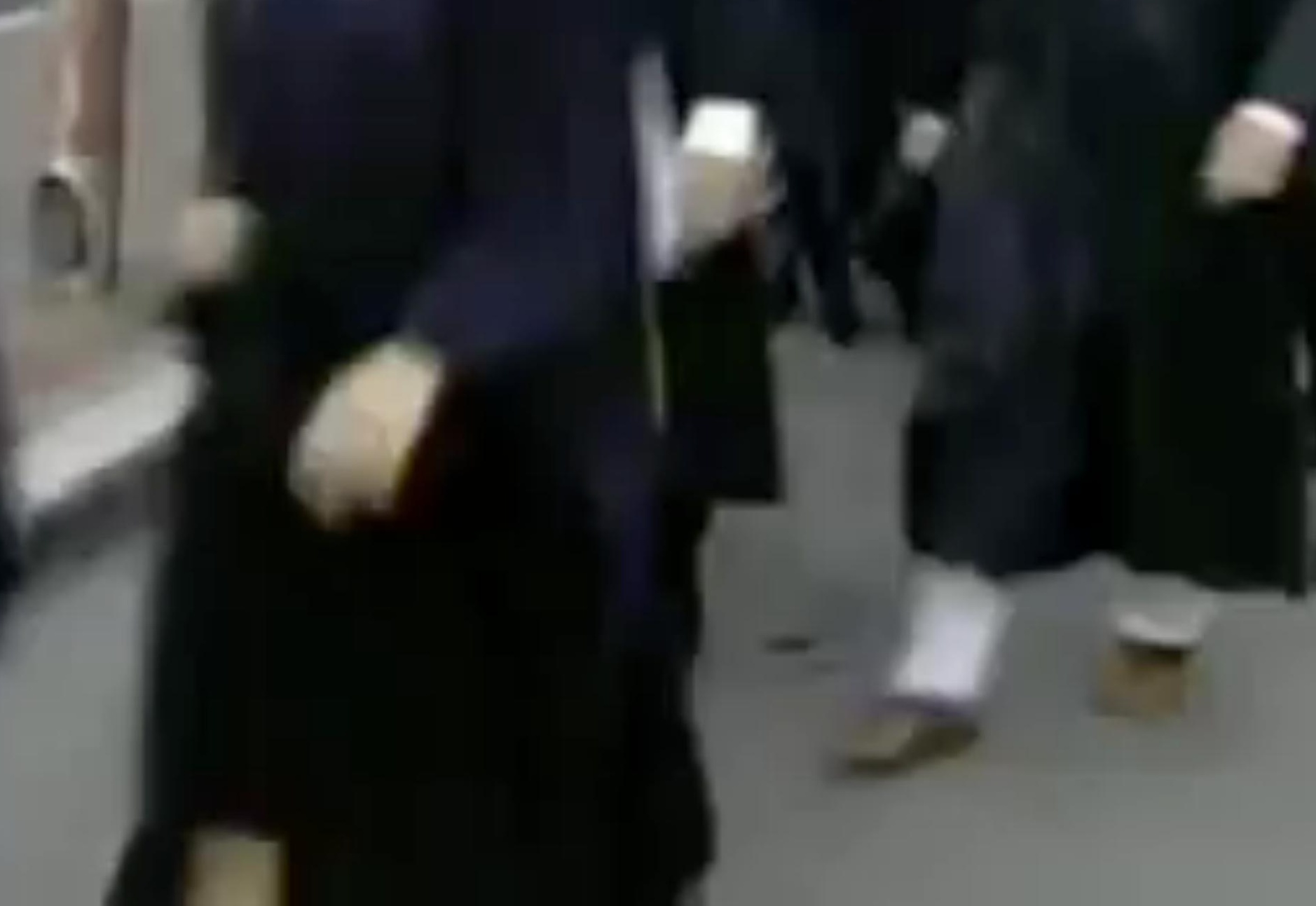

1

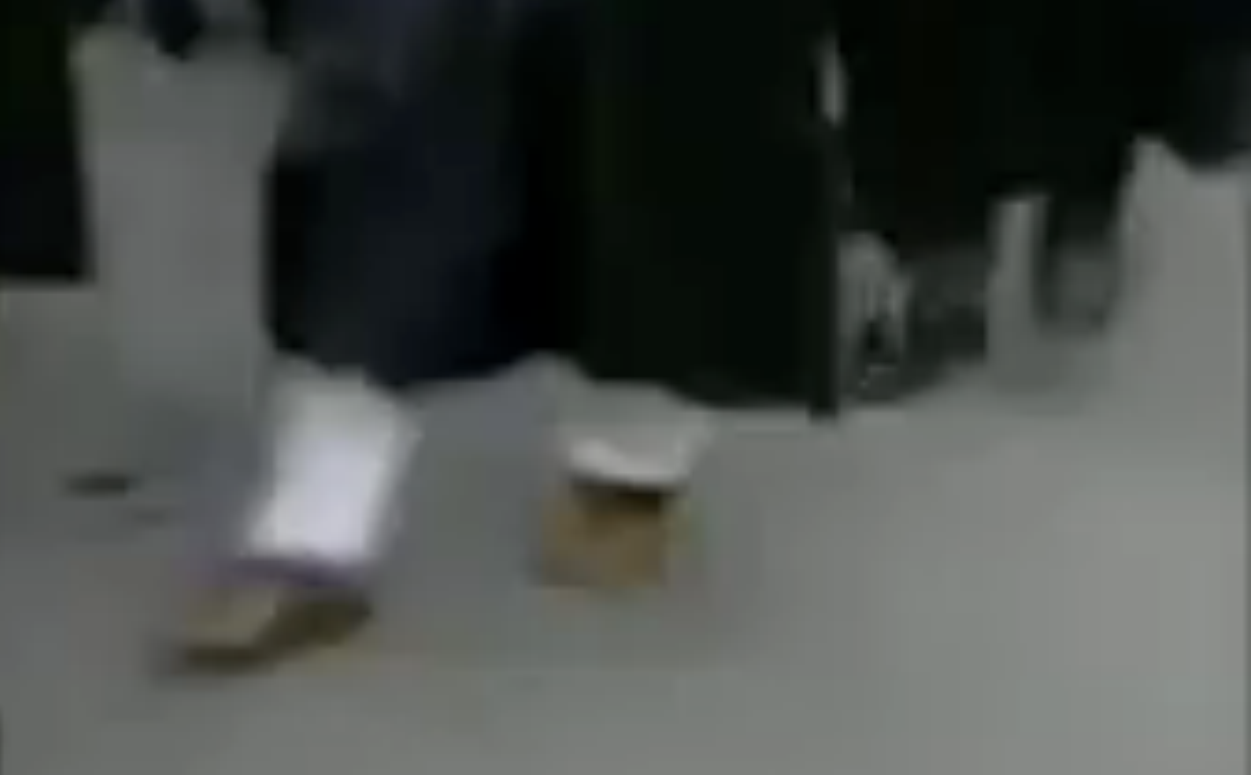



1. Students don't understand fundamental concepts 
1. Students don't understand fundamental concepts

2. Students don't know what they don't know 


\section{Students don't understand fundamental}

Copyright 1999 by the American Psychological Association, Inc.
$0022-3514 / 99 / \$ 3.00$

\section{Stund}

Joumal of Personality and Social

1999, vol. 77, No.

Unskilled and Unaware of It: How Difficulties in Recognizing One's Own
Incompetence Lead to Inflated Self-Assessments

Justin Kruger and Daversity

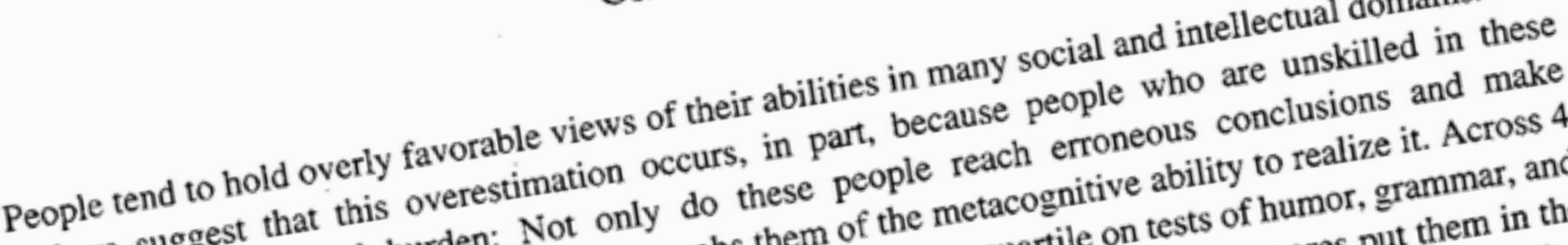
authors suggest that this burden: Not only do these mef the metacognitive abilite humor, grammar, and domains suffechoices, but their incompetents scoring in the bottom. Although their test sced this miscalibration 
Day 7

Day 6

Day 5

Day 4
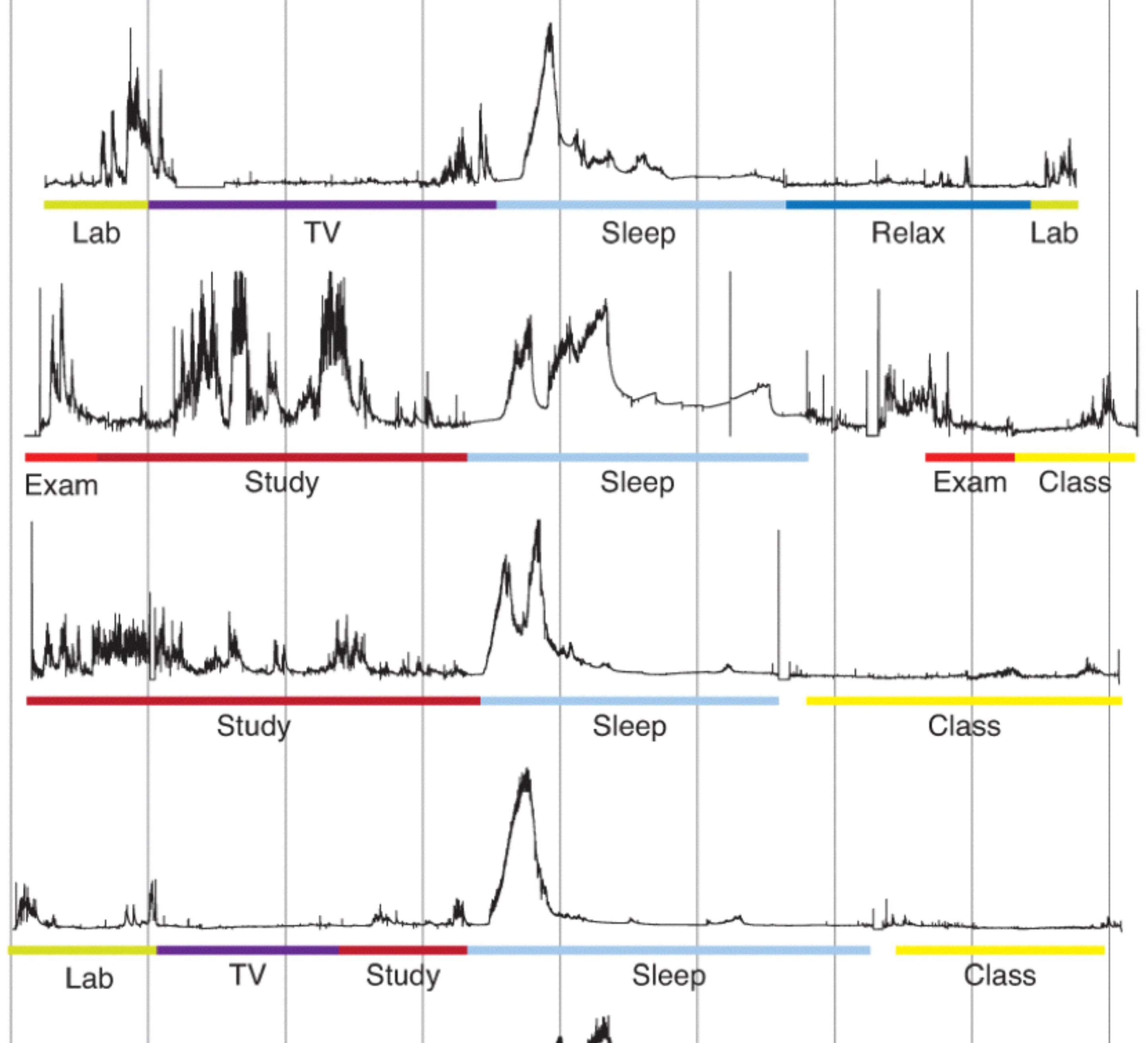


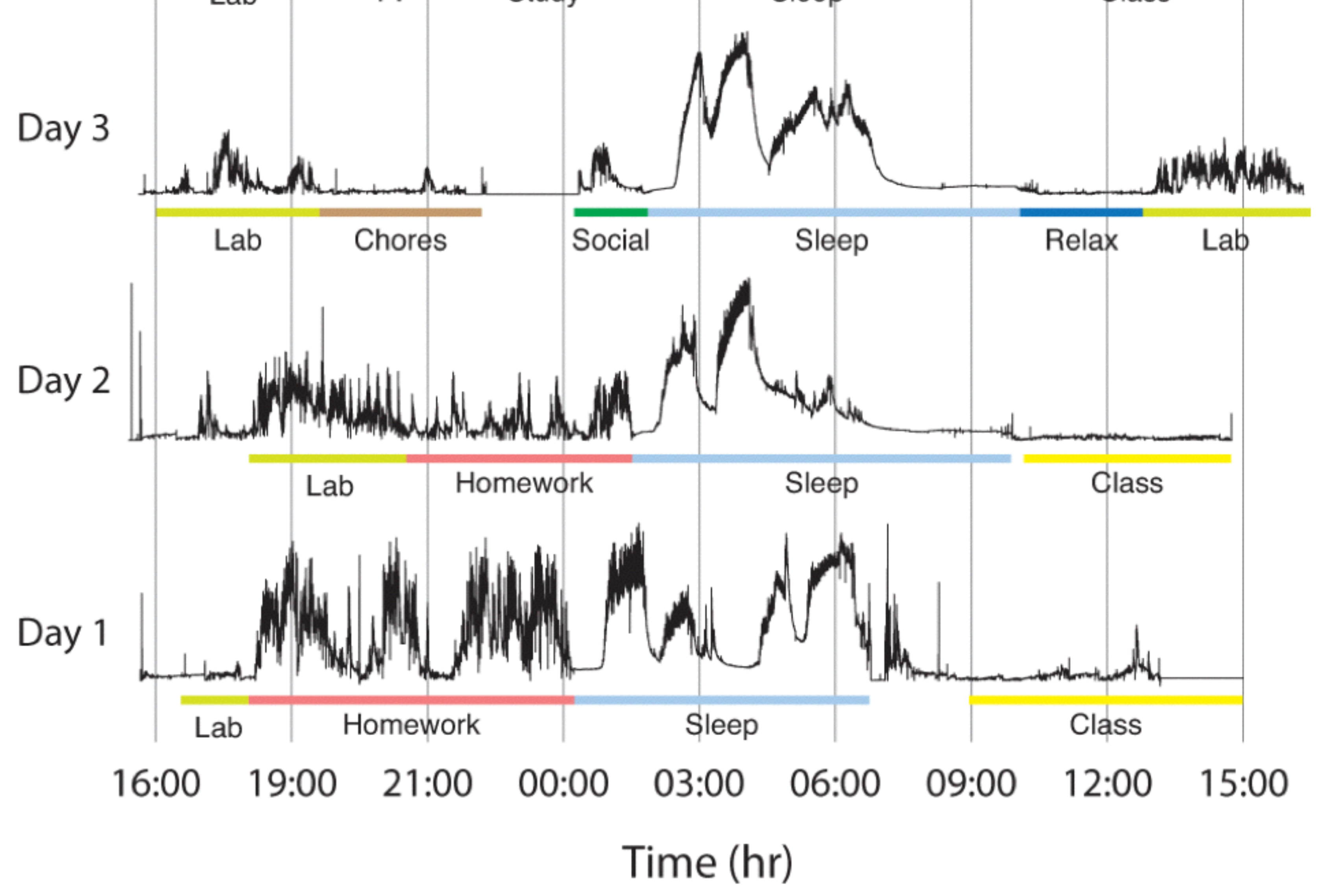

Source: Poh, M. Z., Swenson, N. C., \& Picard, R. W. (2010). A Wearable Sensor for Unobtrusive, Long-Term Assessment of Electrodermal Activity. IEEE Transactions on Biomedical Engineering 57(5). 
1. Students don't understand fundamental concepts

2. Students don't know what they don't know

3. We are not engaging students in enough meaningful practice in class 


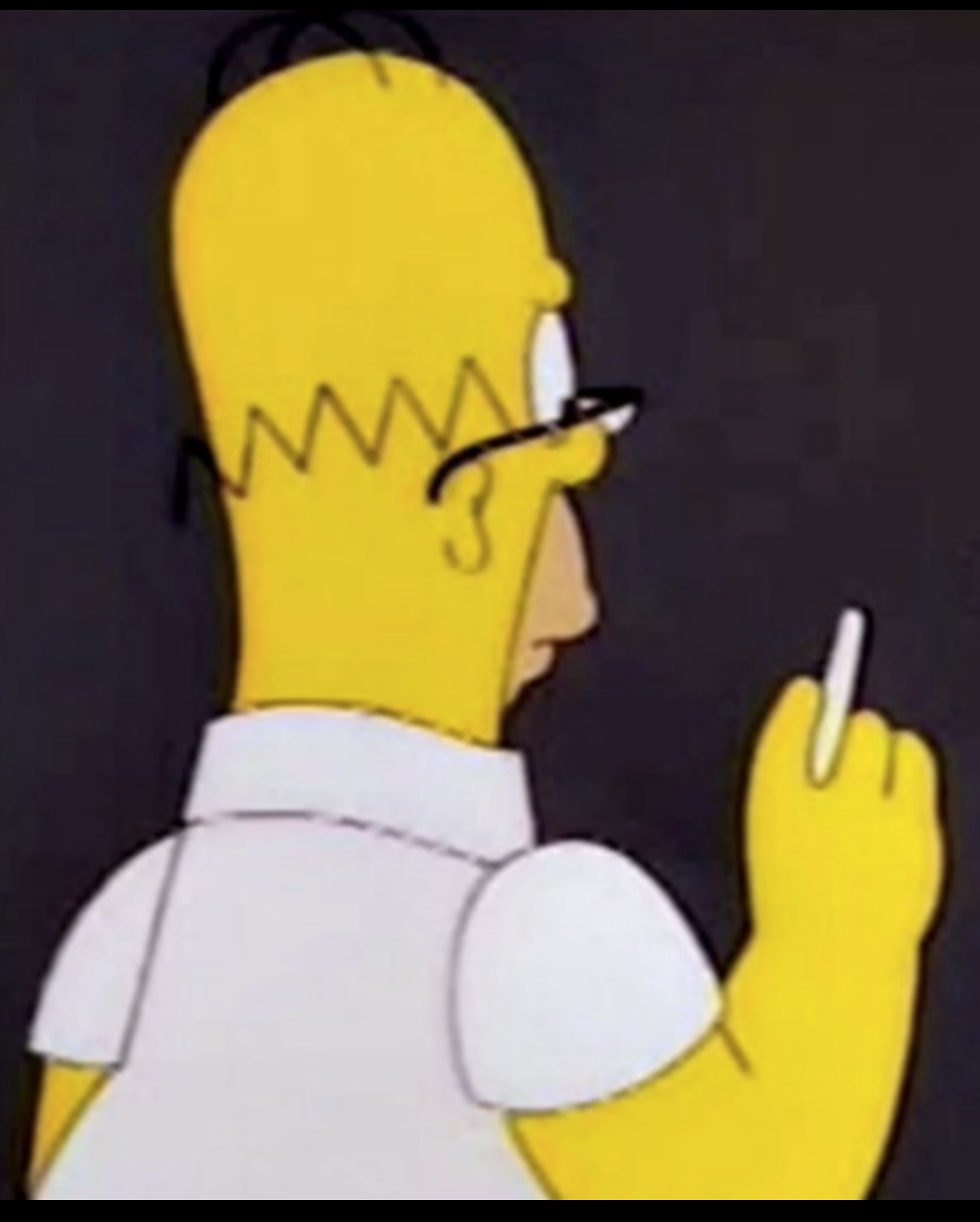

$$
\begin{aligned}
& M\left(H^{\circ}\right)=\pi\left(\frac{1}{137}\right)^{8} \sqrt{\frac{h c}{G}} \\
& 3987^{12}+4365^{12}-4472^{12} \\
& \Omega\left(t_{0}\right)>1 \\
& (\Omega) . \Omega ?
\end{aligned}
$$


Technology is the answer! 
Technnmengy, is the-entswer! 
Technnmengy, is the andswer!

Technology is a vehicle for pedagogical change. 

Assessment 


\section{Assessment}

\section{formative}

summative 


\title{
Assessment
}

\section{formative}

\section{summative}

\author{
Goal: Accurately \\ measure student \\ understanding for \\ purposes of giving a \\ grade
}




\section{Assessment}

\section{formative}

\section{summative}

Goal: Improve instruction by identifying strengths and weaknesses
Goal: Accurately measure student understanding for purposes of giving a grade 


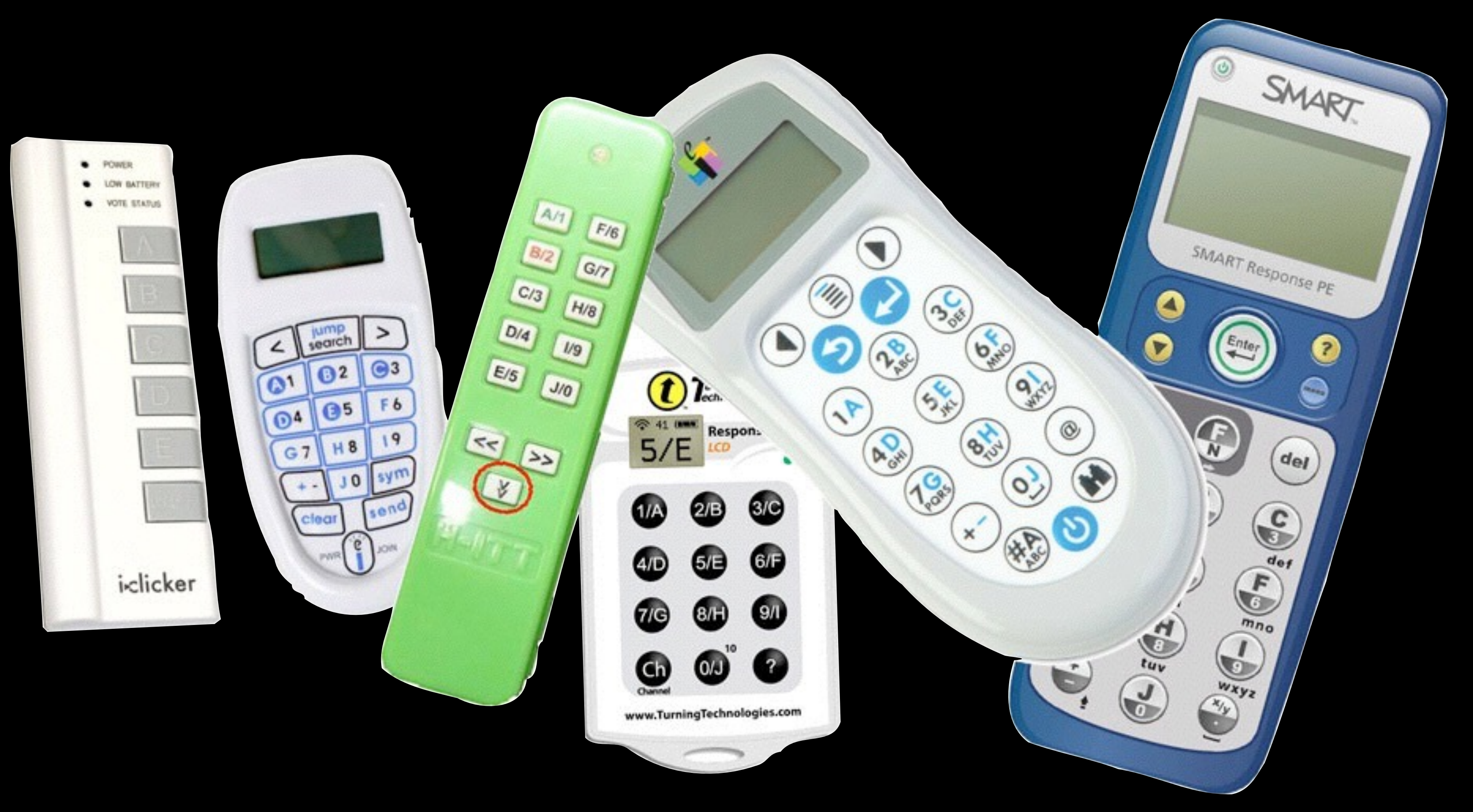




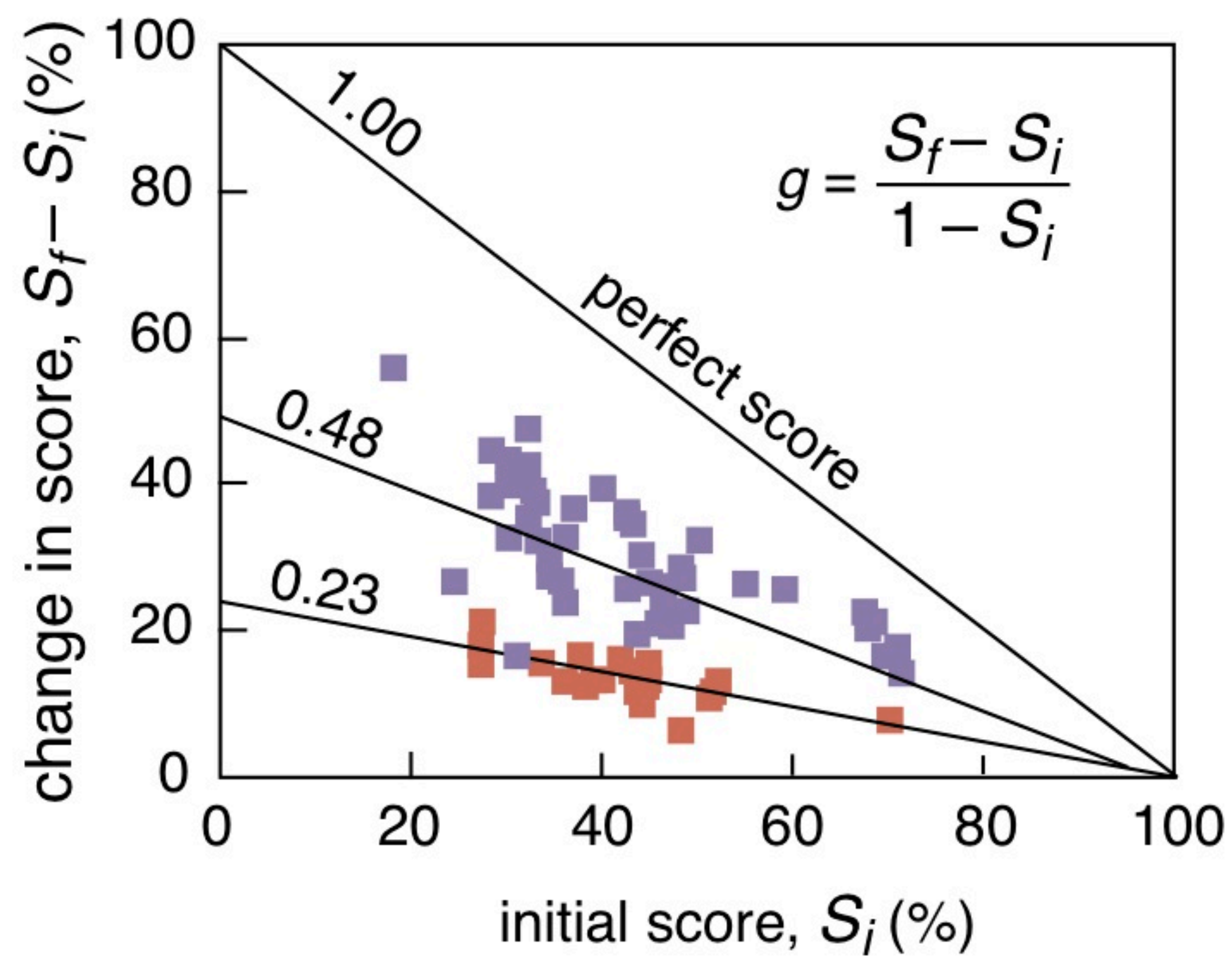

\section{Interactive teaching Traditional lecture}

Source: Hake, R. R. (1998). Interactive-engagement versus traditional methods: A six-thousand-student survey of mechanics test data for introductory physics courses. Am. J. Phys. 66(1). 
If it ain't broke...? 


\section{Limitations of traditional clicker questions}




\section{Learning objective:}

Students understand how transformations of a random variable do or do not impact its variance / SD 
If $X$ is a random variable, then $\mathrm{SD}(1-X)$

A. is less than $\operatorname{SD}(X)$.

$B$. is equal to $\operatorname{SD}(X)$.

C. is greater than $\mathrm{SD}(X)$.

D. cannot be determined. 
Student answers correctly

\section{Student understands} the concept 
Student answers correctly
Student understands the concept 
If $X$ is a random variable, then $\mathrm{SD}(1-X)$

A. is less than $\operatorname{SD}(X)$.

$B$. is equal to $\operatorname{SD}(X)$.

C. is greater than $\mathrm{SD}(X)$.

D. cannot be determined. 
If $X$ is a random variable, then $\mathrm{SD}(1-X)$

A. is less than $\operatorname{SD}(X)$.

$B$. is equal to $\operatorname{SD}(X)$.

C. is greater than $\mathrm{SD}(X)$.

D. cannot be determined. 

If a student selected the right answer, did they: 
If a student selected the right answer, did they:

- understand the concept? 
If a student selected the right answer, did they:

- understand the concept?

- recall a rule they read in the textbook? 
If a student selected the right answer, did they:

- understand the concept?

- recall a rule they read in the textbook?

- guess? 

If a student selected the right answer, they might think: 
If a student selected the right answer, they might think:

- I understand the concept! 

If a student selected a wrong answer, did they: 
If a student selected a wrong answer, did they:

- have a specific misconception (which one?) 
If a student selected a wrong answer, did they:

- have a specific misconception (which one?)

- try to blindly apply a rule, but fail? 
If a student selected a wrong answer, did they:

- have a specific misconception (which one?)

- try to blindly apply a rule, but fail?

- guess incorrectly? 


\section{Challenges with peer discussion quality}


How can we make use of the Data? 
How can we make use of the data? 
More sophisticated devices, that students already have

More sophisticated activities and thinking processes 
learning | catalytics 


\section{learning | catalytics}

Developed at Harvard starting in 2010 


\section{learning | catalytics}

Developed at Harvard starting in 2010

Spun out into a startup in 2011 


\section{learning | catalytics}

Developed at Harvard starting in 2010

Spun out into a startup in 2011

Acquired by Pearson in 2013 


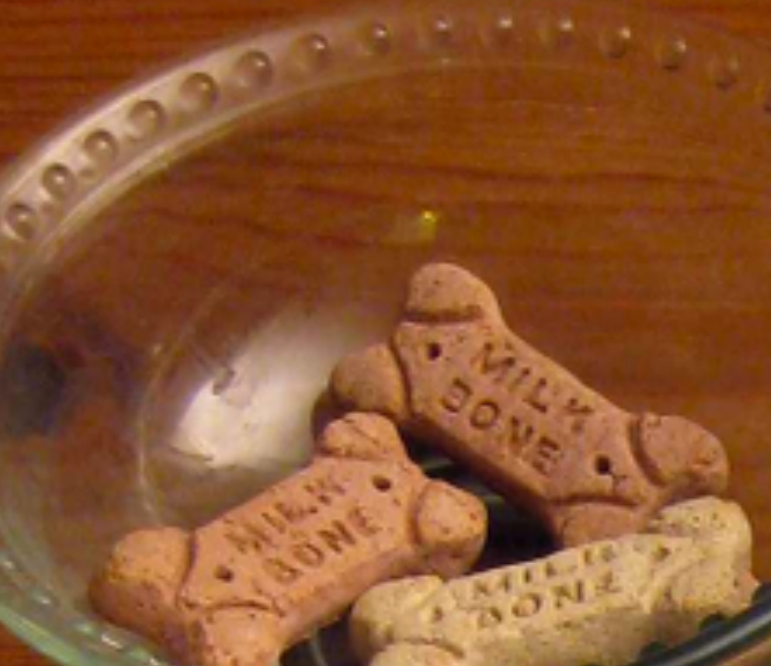

(d)
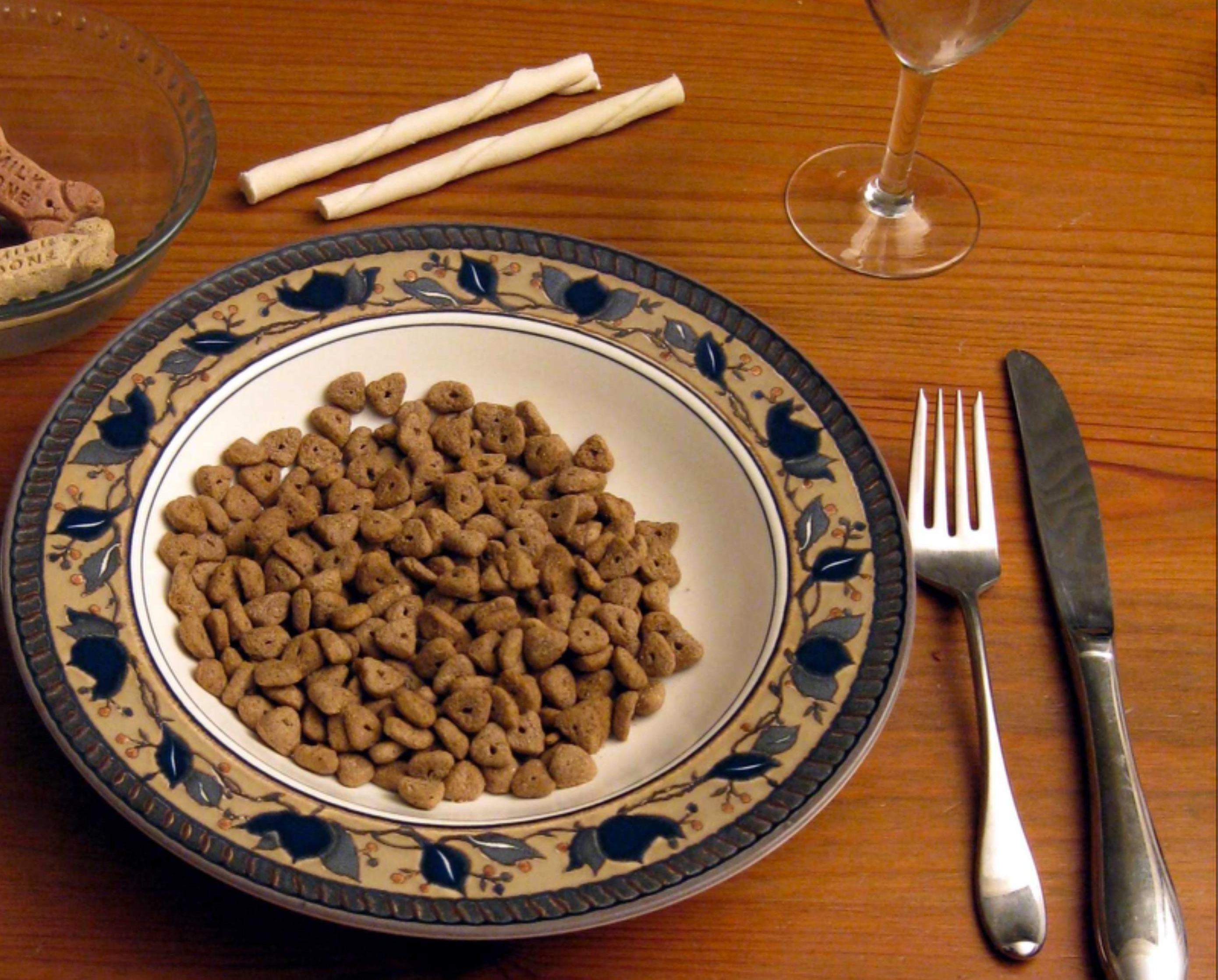

\& 80,25 


\section{eating our own dog food}
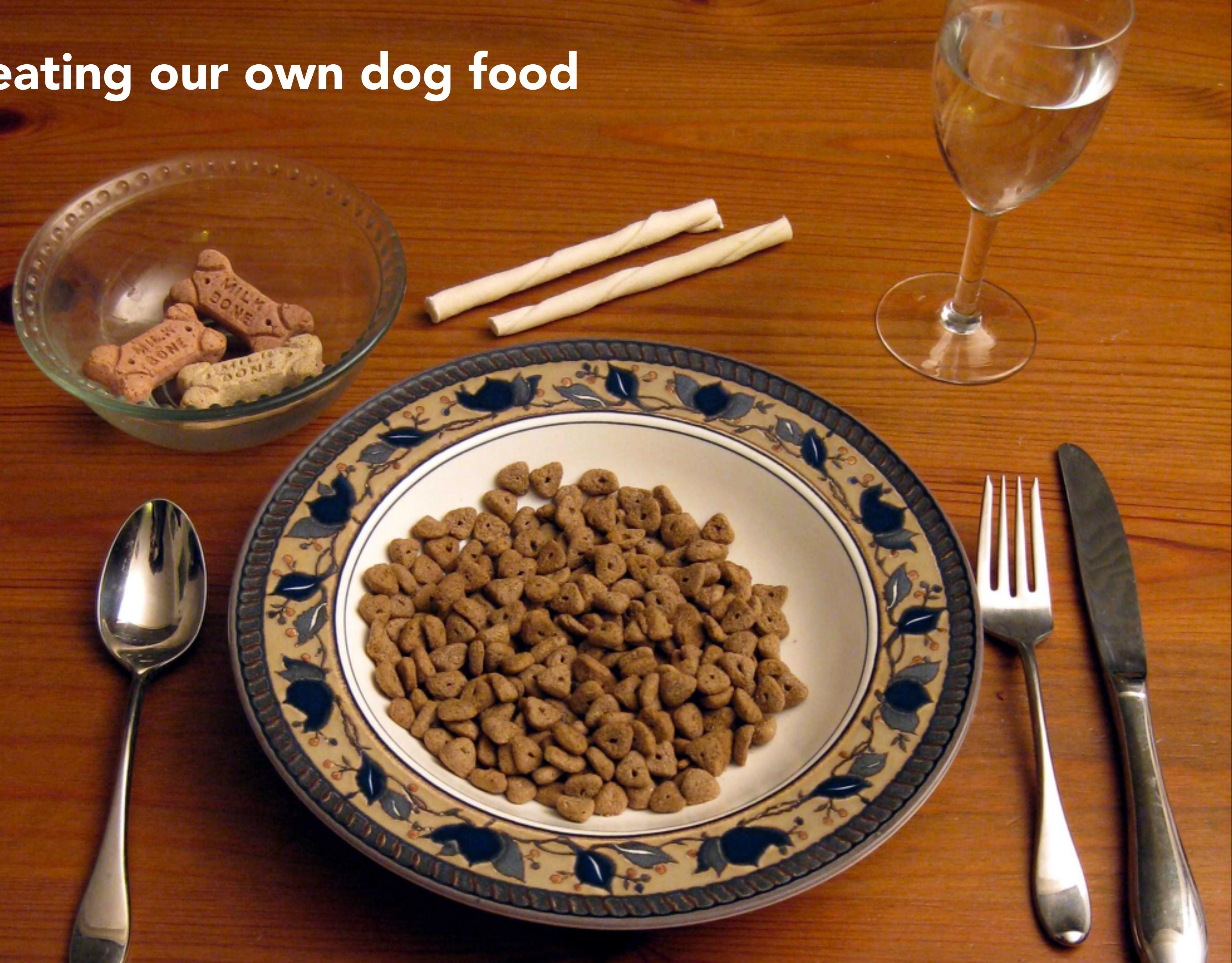
If $X$ is a random variable, then $\mathrm{SD}(1-X)$

A. is less than $\operatorname{SD}(X)$.

$B$. is equal to $\operatorname{SD}(X)$.

C. is greater than $\mathrm{SD}(X)$.

D. cannot be determined. 
Here is the histogram for points scored. On top of this histogram, draw a histogram for another variable that would have the SAME standard deviation as points scored.

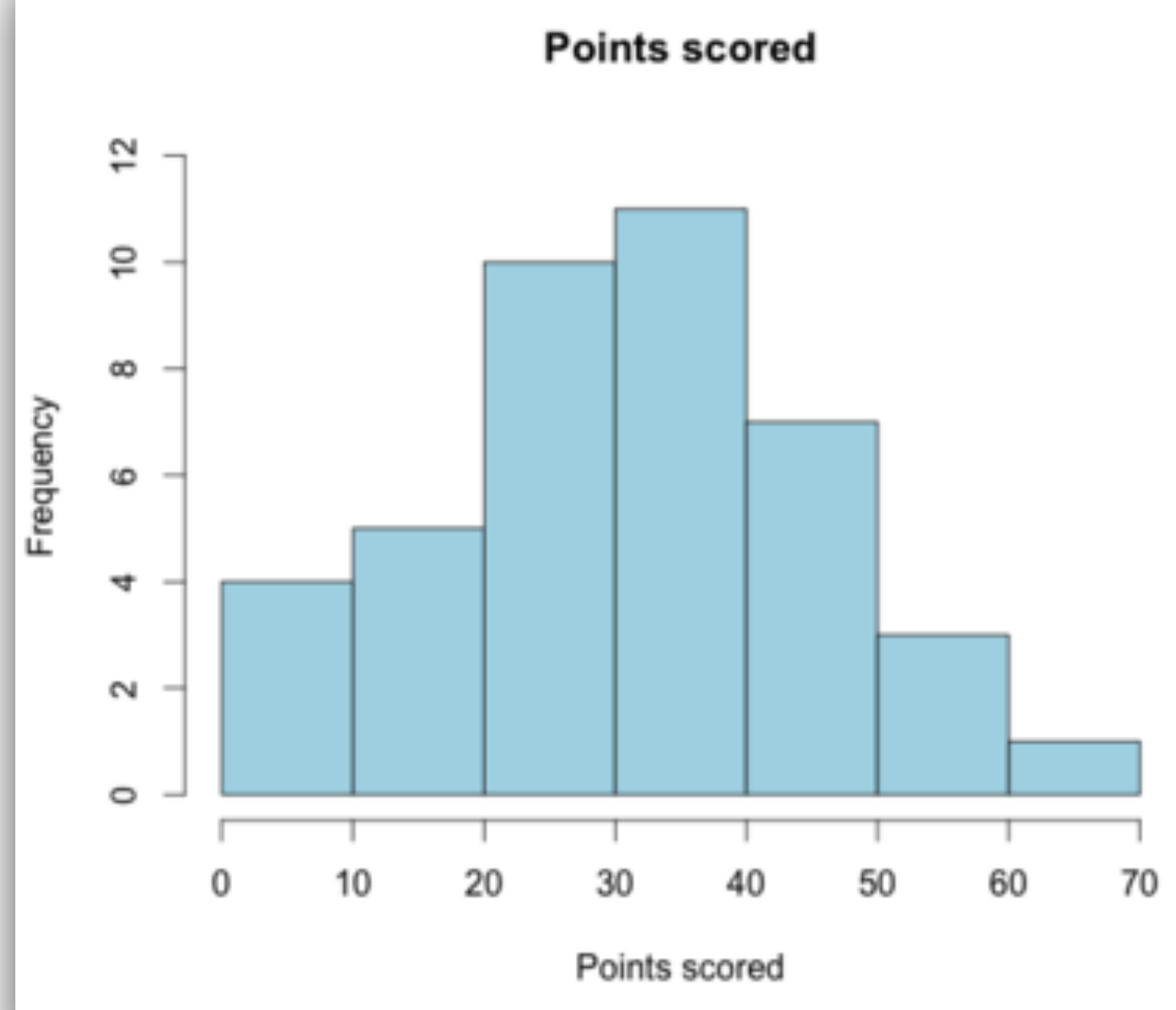




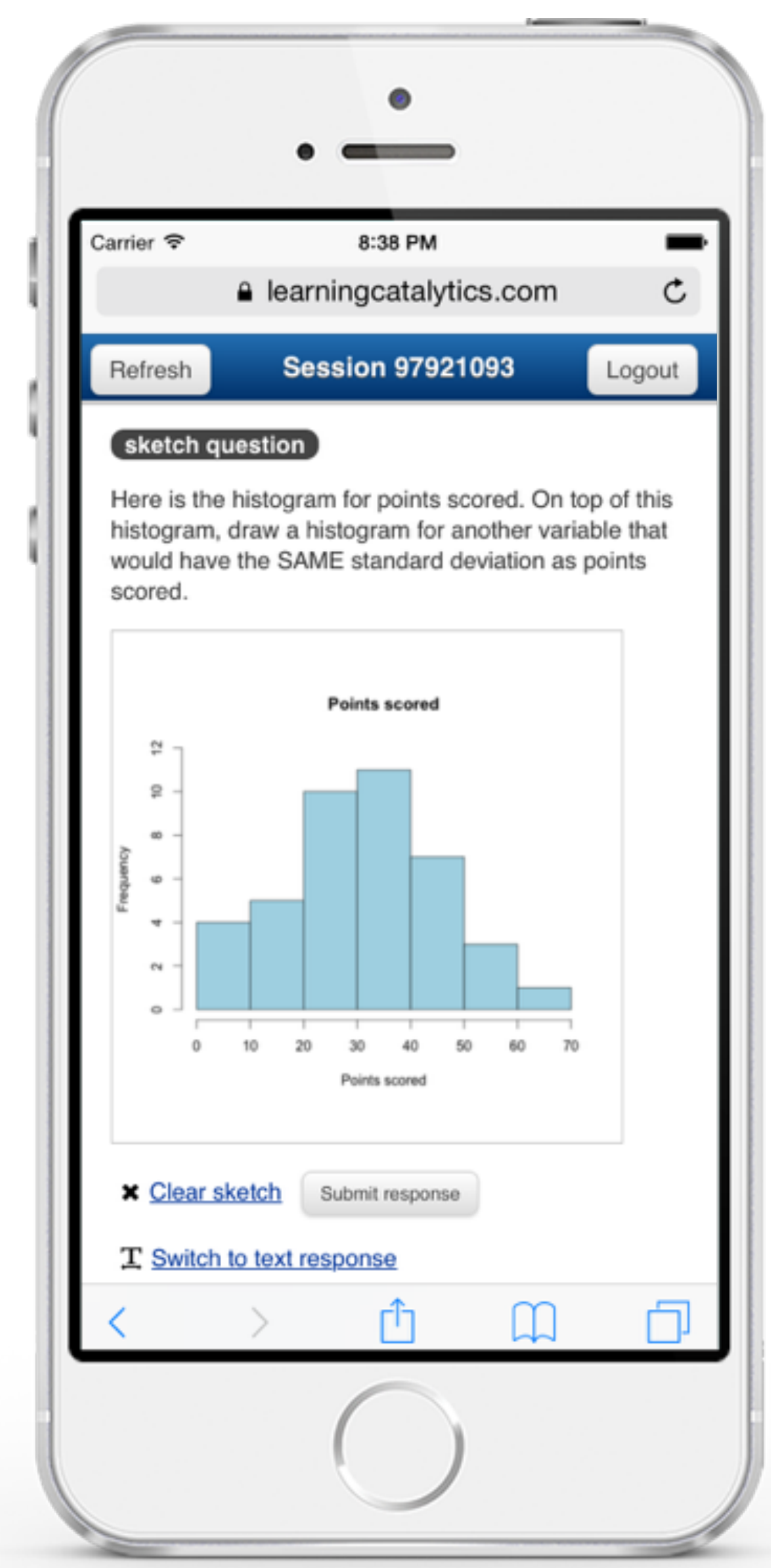




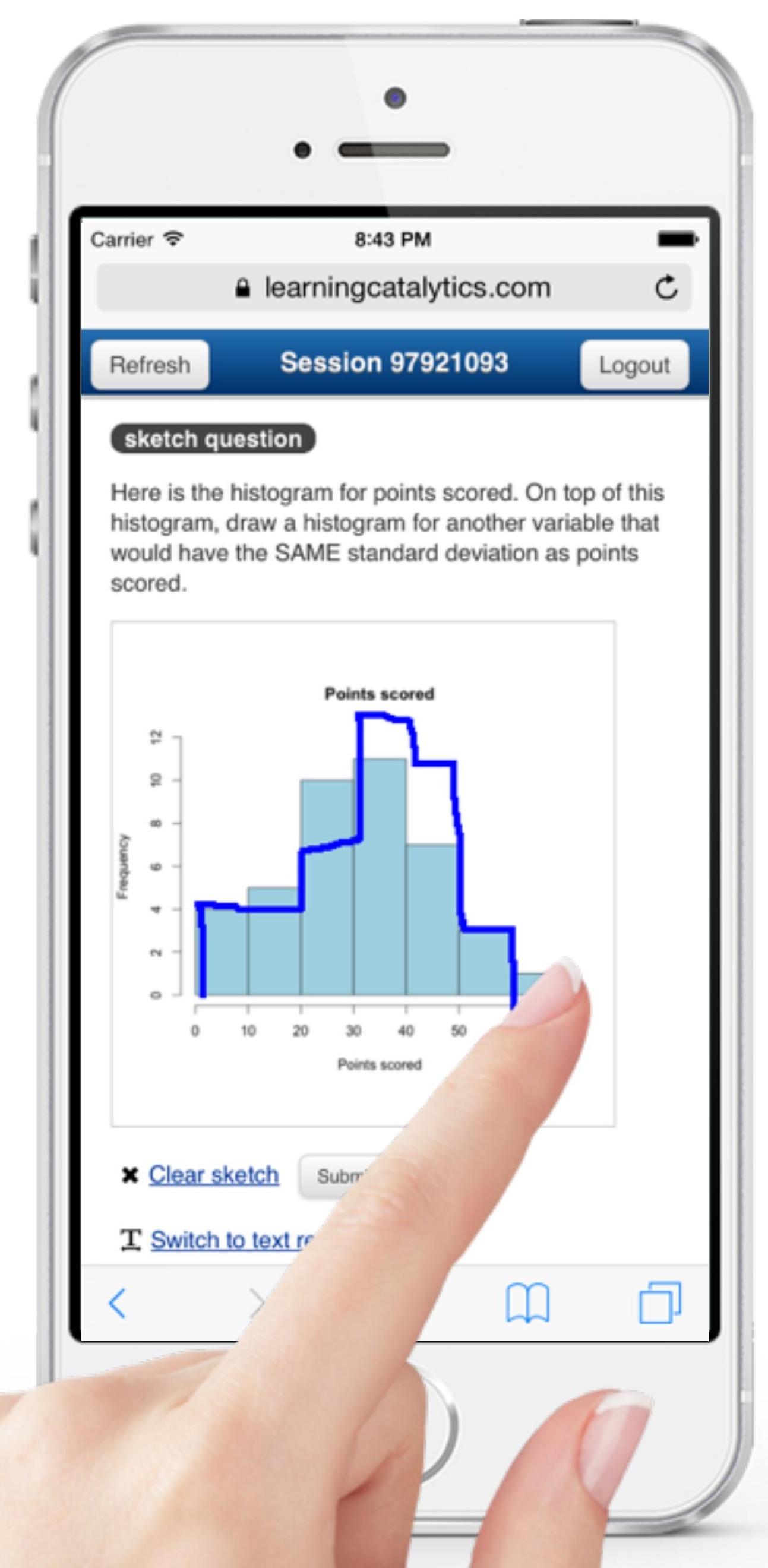



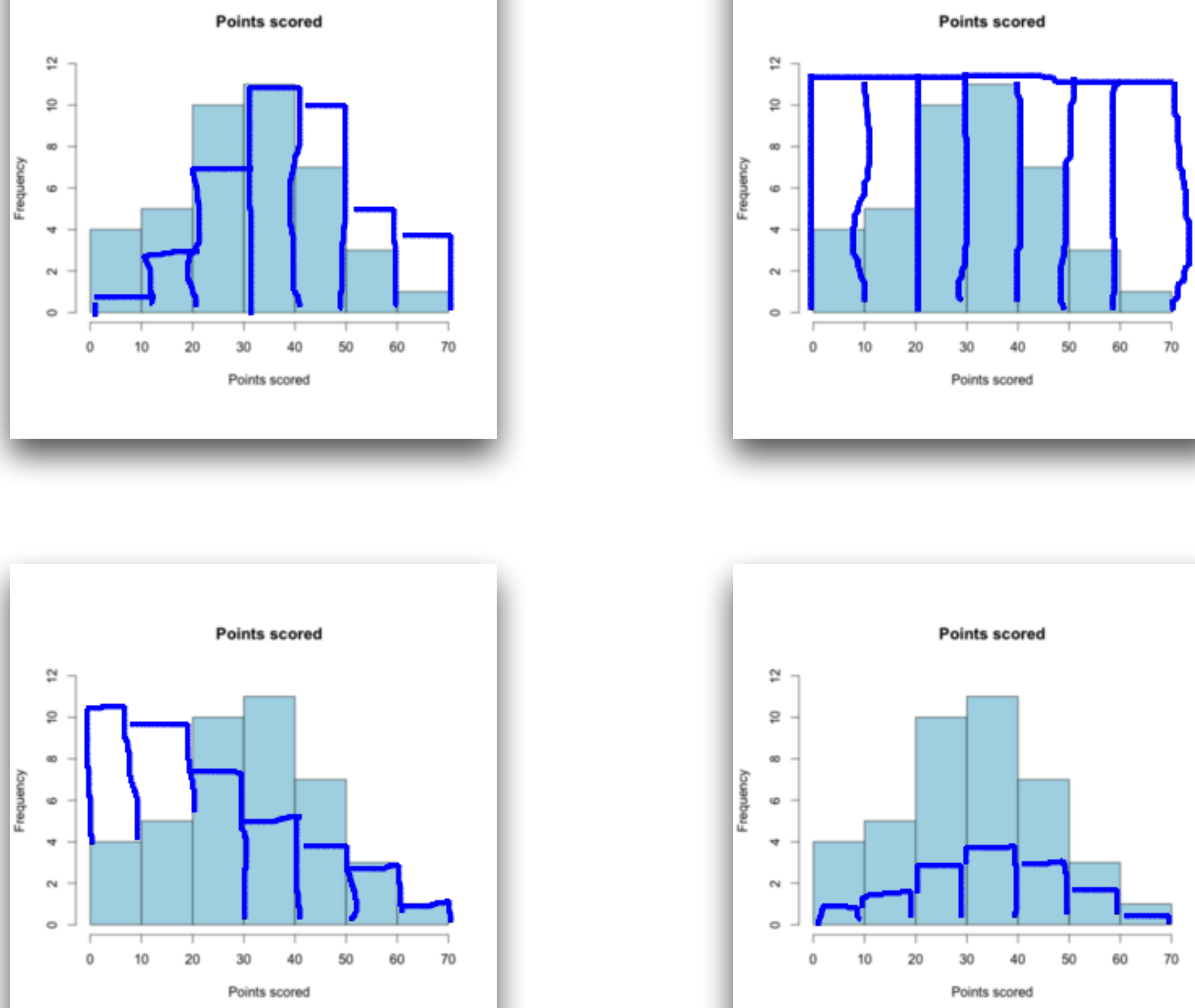

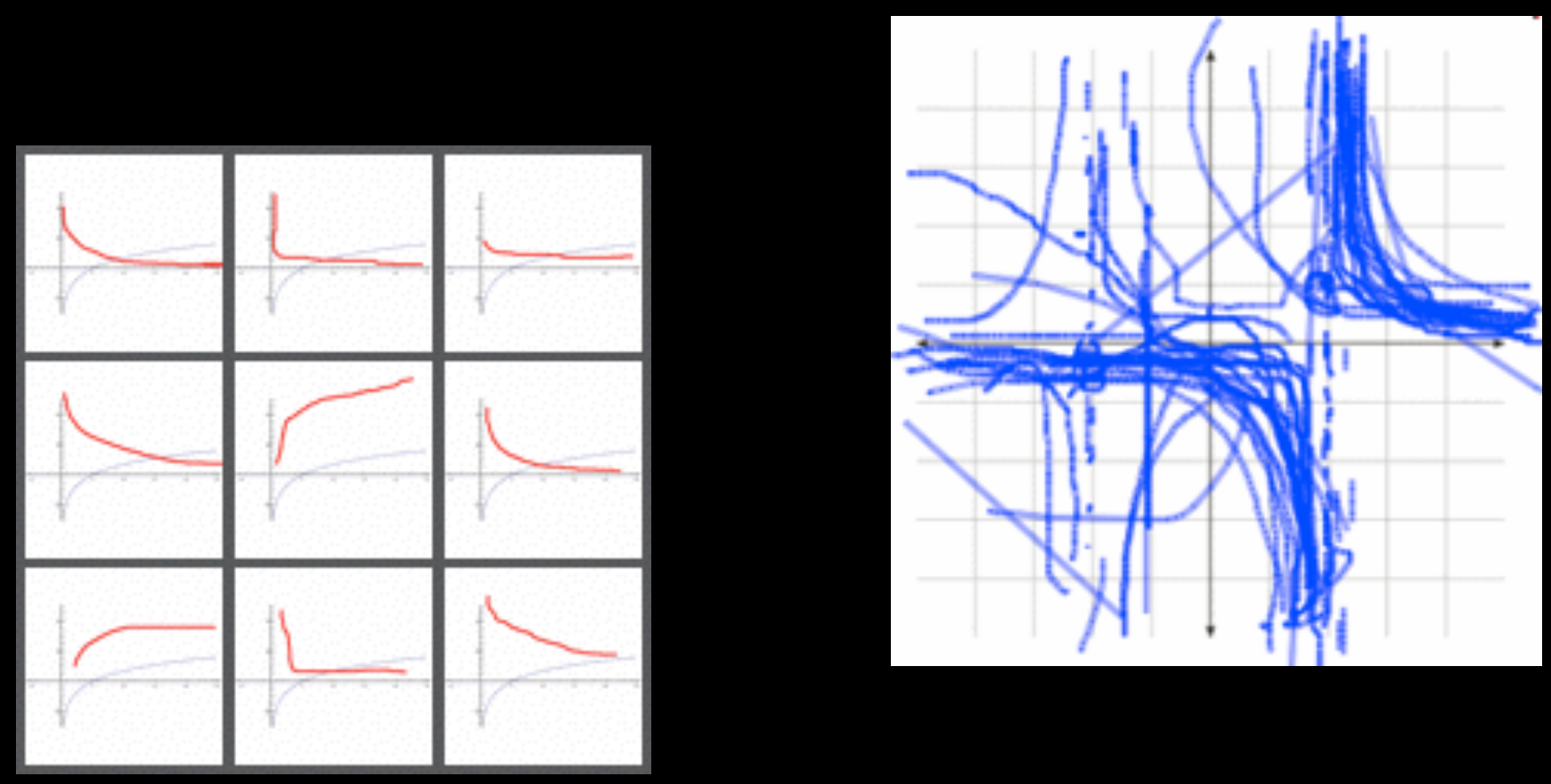

\begin{tabular}{|l|}
\hline $15 x \wedge 5: 25 \%$ \\
$16 x \wedge 5: 6 \%$ \\
$2.5 x \wedge 3-2.5: 6 \%$ \\
$25 x \wedge 4 / 2: 6 \%$ \\
$3 x \wedge 2(5 x \wedge 3): 6 \%$ \\
$5(x \wedge 3)(3 x \wedge 2): 6 \%$ \\
$5 x \wedge 3: 31 \%$ \\
$5 x \wedge x^{\star} 3 x: 6 \%$ \\
$f(x \wedge 2)(2 x): 6 \%$ \\
\hline
\end{tabular}
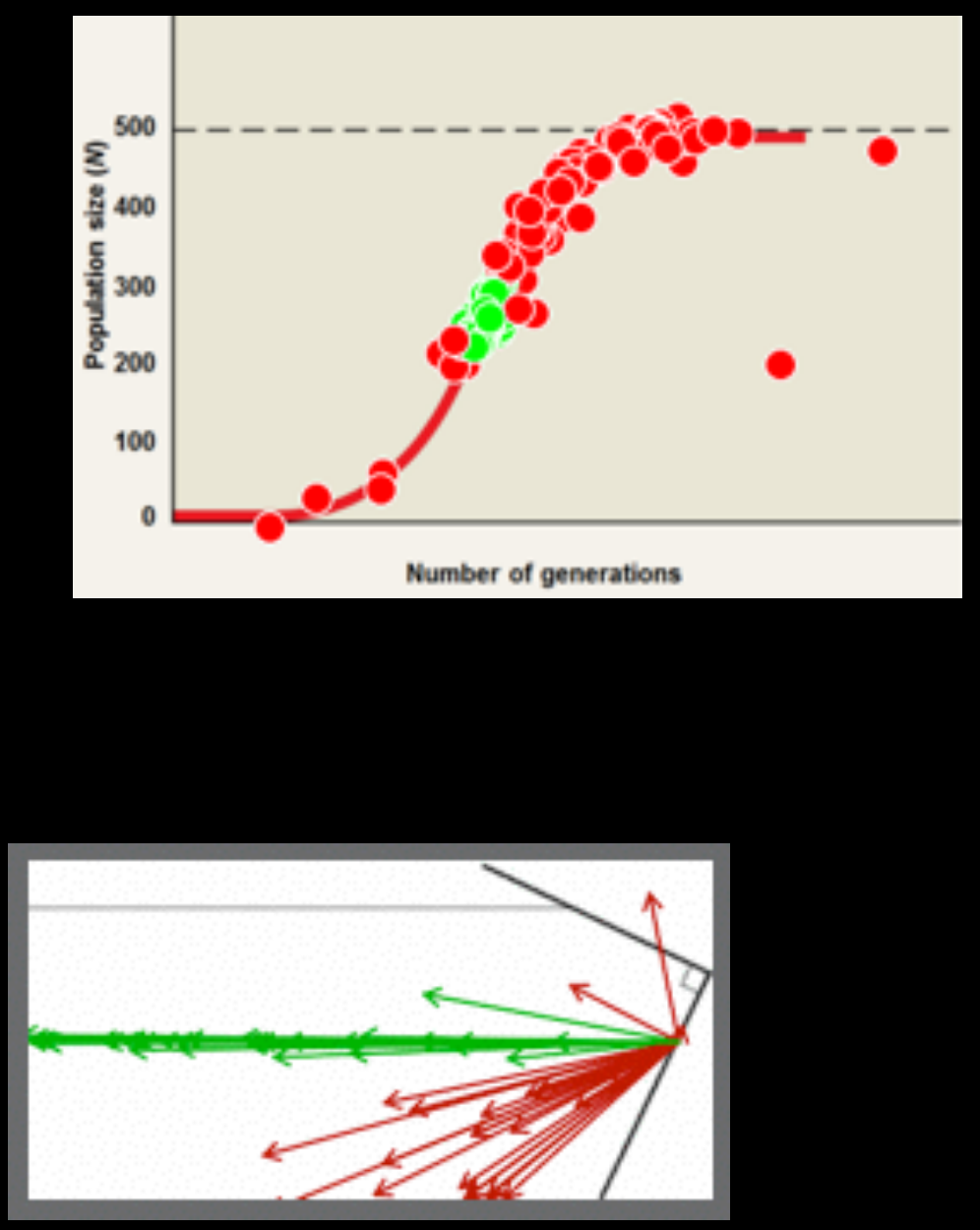

\begin{tabular}{|l|}
\hline $2: 2 \%$ \\
\hline$-1 / 2: 10 \%$ \\
\hline $.5: 38 \%$ \\
\hline $1 / 2: 29 \%$ \\
\hline $0.5: 14 \%$ \\
\hline$-x \wedge(-1): 2 \%$ \\
\hline$-.5: 2 \%$ \\
\hline$-3 / 2: 2 \%$ \\
\hline
\end{tabular}

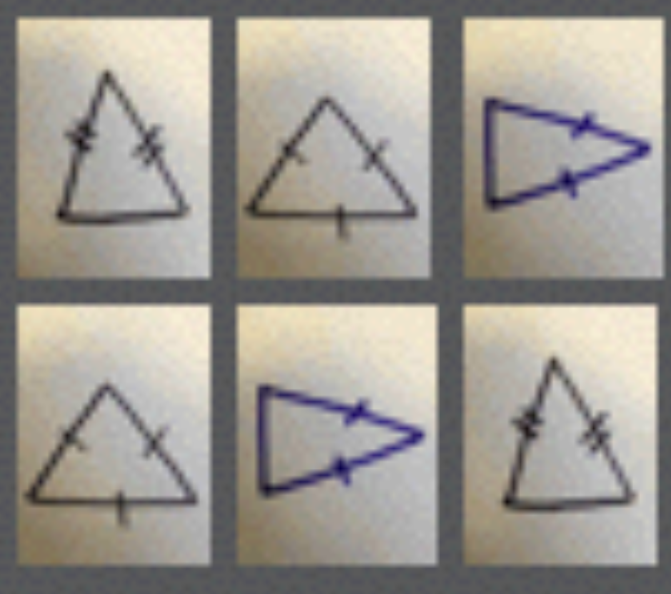




\section{learning |catalytics}

Brian Lukoff | Pearson | Log out

Courses Questions Classrooms Tour Help

Student view

\section{Classrooms $>$ Science Center B}

+ Add seat + Add block of size 5 : across $\times 5$ : down ? Instructions

back of room

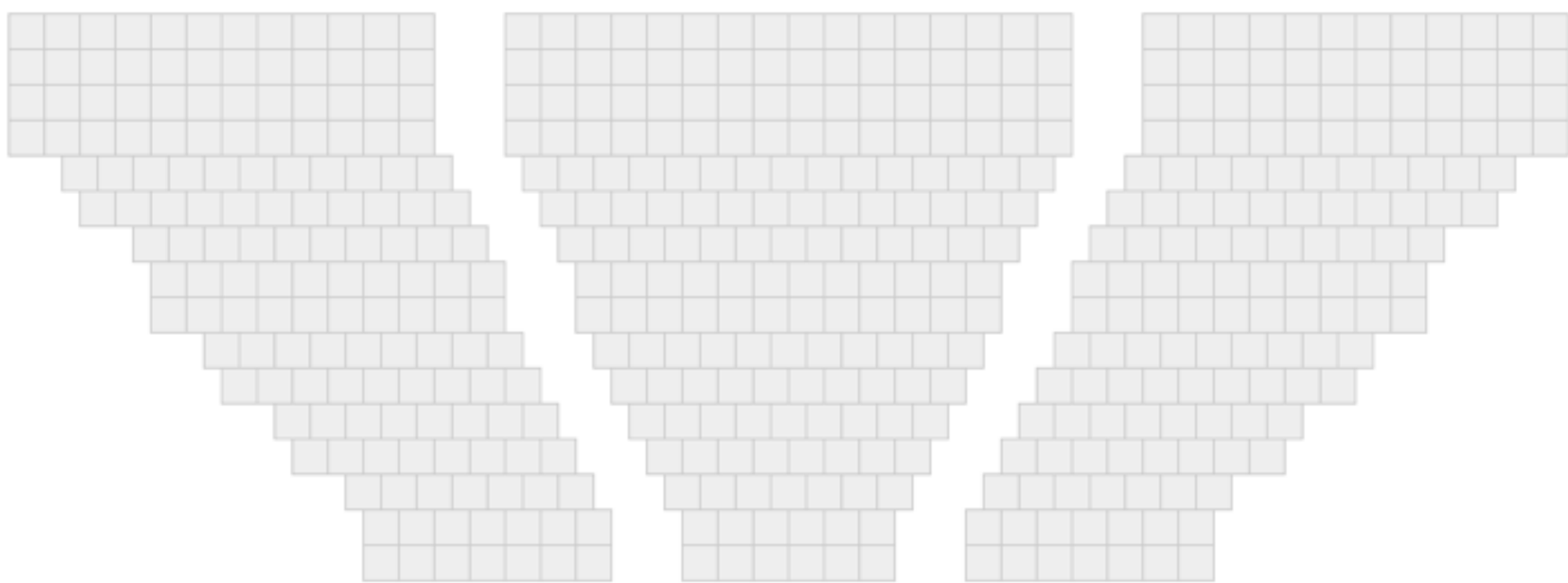

front of room

Name*

\section{Science Center B}

Save 


\section{learning|catalytics}

Brian Lukoff | Pearson | Log out

Courses Questions Classrooms Tour Help

Student view

\section{Classrooms $>$ Science Center B}

+ Add seat + Add block of size 5 : across $\times 5 \quad$ : down ? Instructions

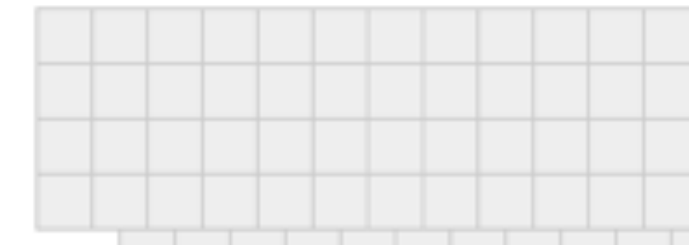

back of room

Carrier $\curvearrowright$

5:21 PM

- learningcatalytics.com

c

Select seat

Logout

Enter the seat number you are sitting in:

D15 or Q Show seat map

Click the seat you are sitting in:

$<$ Scroll left

$>$ Scroll right

front of room

front of room

Name*

Science Center B

Save 


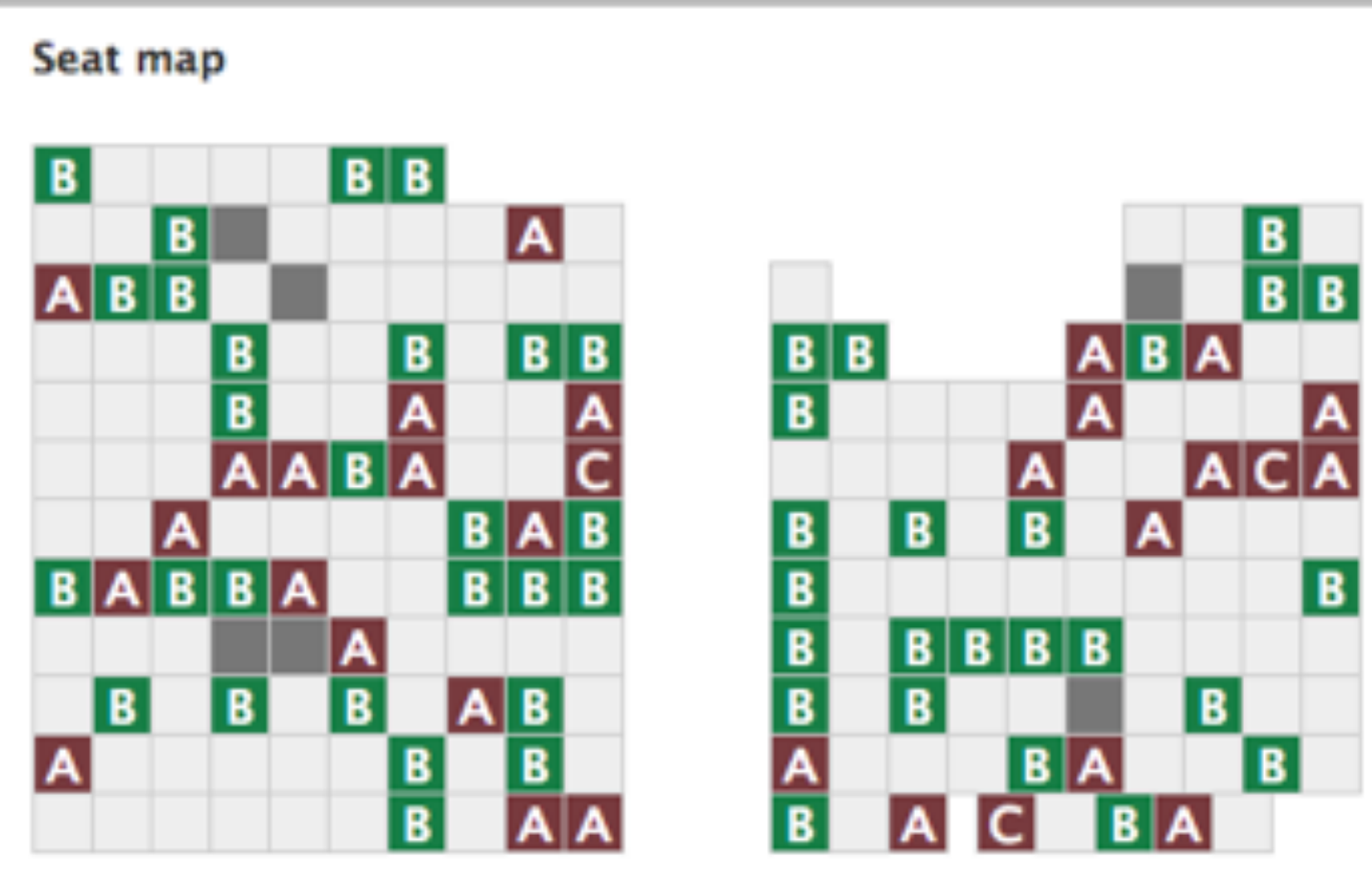




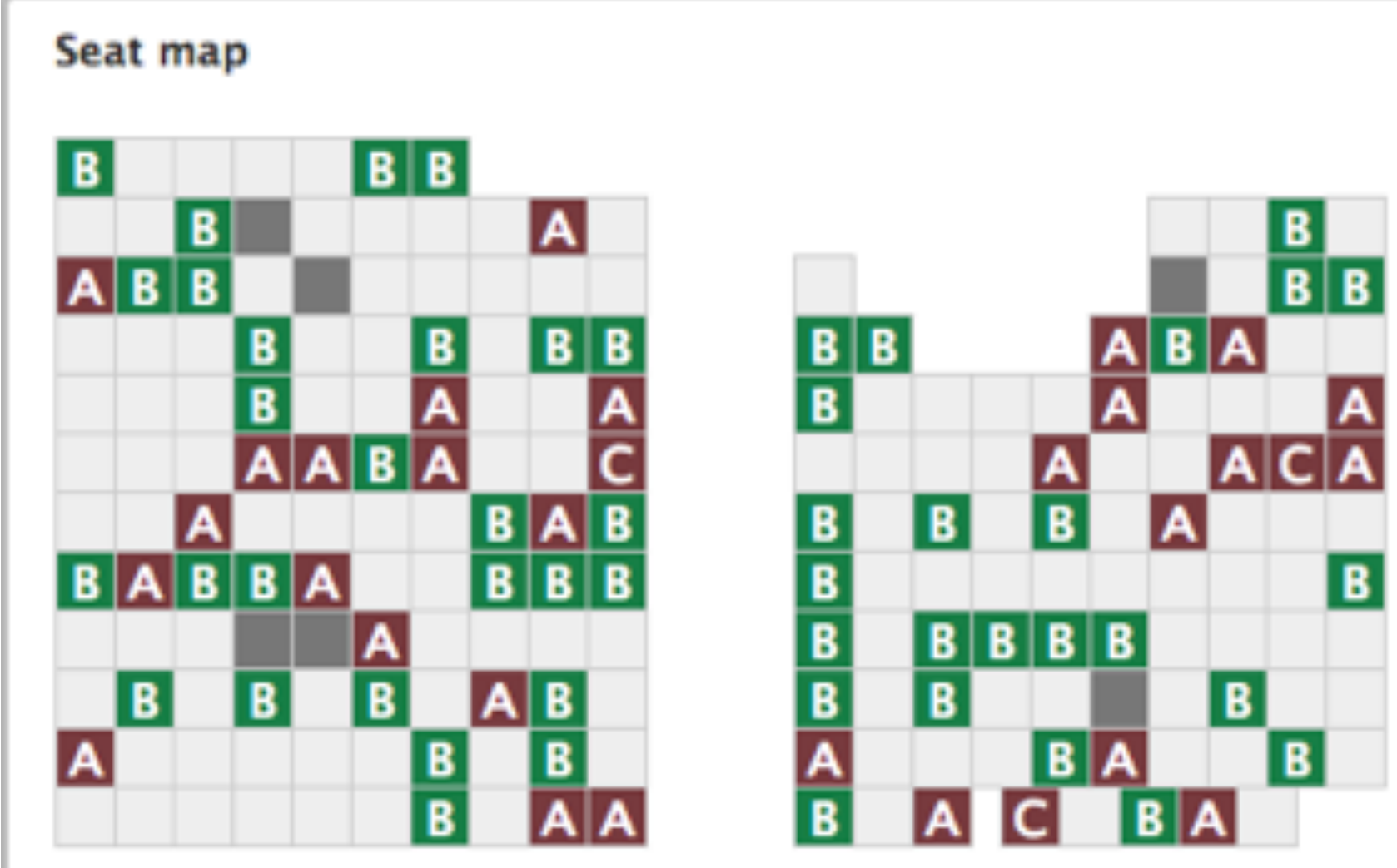

a learningcatalytics.com

C

\begin{tabular}{lll} 
Refresh Session $26472566 \quad$ Logout \\
\hline
\end{tabular}

multiple choice question

A meteorologist predicts a $40 \%$ chance of rain in London and a $70 \%$ chance in Chicago. What is the most likely outcome?

Please discuss your response with:

- Kate Jones (to your right)

- Sarah Smith (to your right)

A. It rains only in London

B. It rains only in Chicago

C. It rains in London and Chicago

D. It rains in London or Chicago 


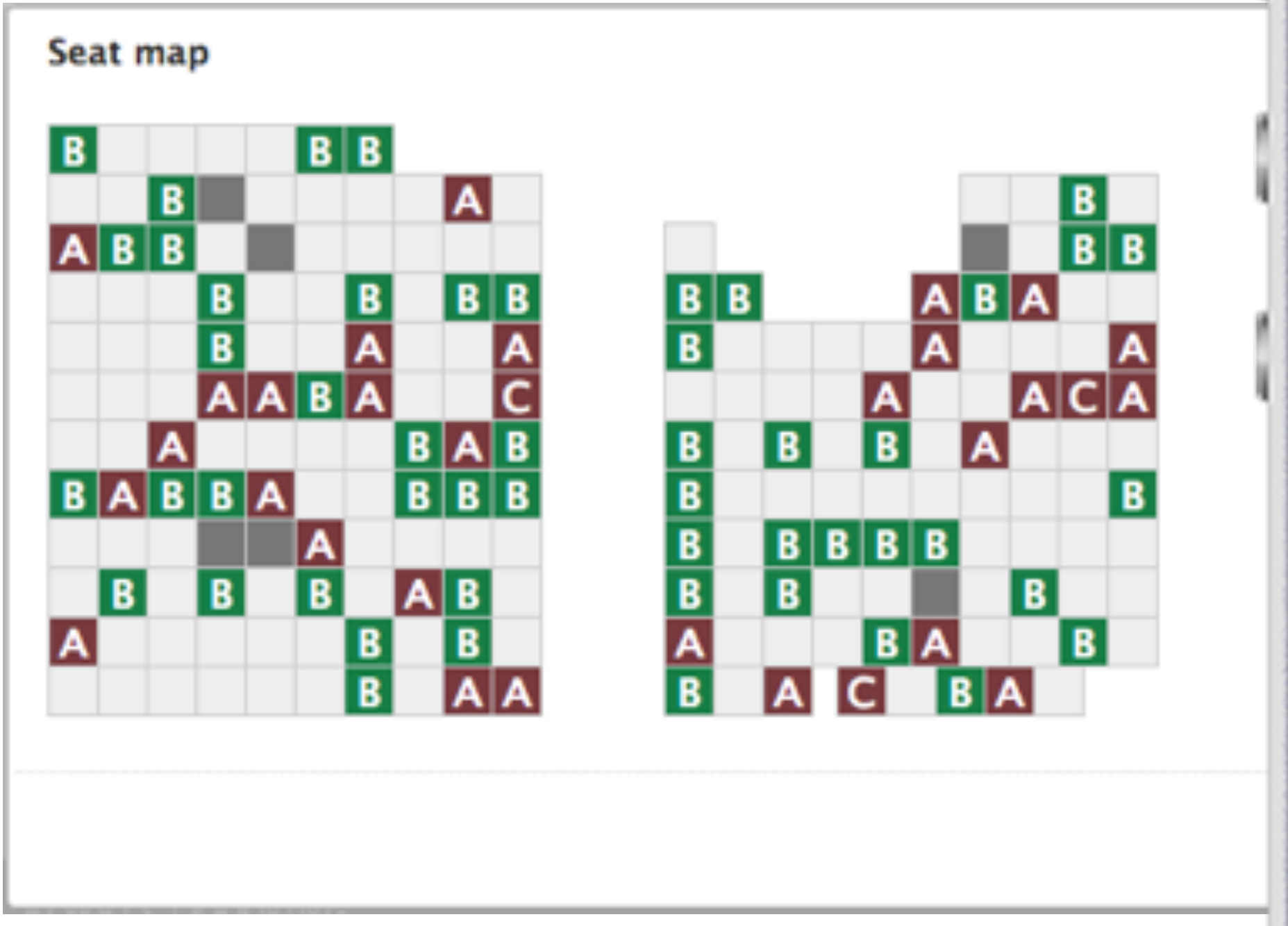

a learningcatalytics.com

C

Refresh Session 26472566

Logout

multiple choice question

A meteorologist predicts a $40 \%$ chance of rain in London and a $70 \%$ chance in Chicago. What is the

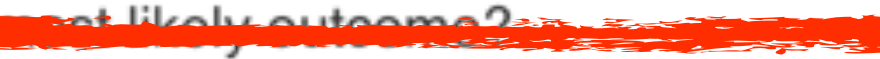

Please discuss your response with:

- Kate Jones (to your right)

- Sarah Smith (to your right)

A. It rains only in London

B. It rains only in Chicago

C. It rains in London and Chicago

D. It rains in London or Chicago 


\section{learning|catalytics}

\section{My Courses > MA 121}

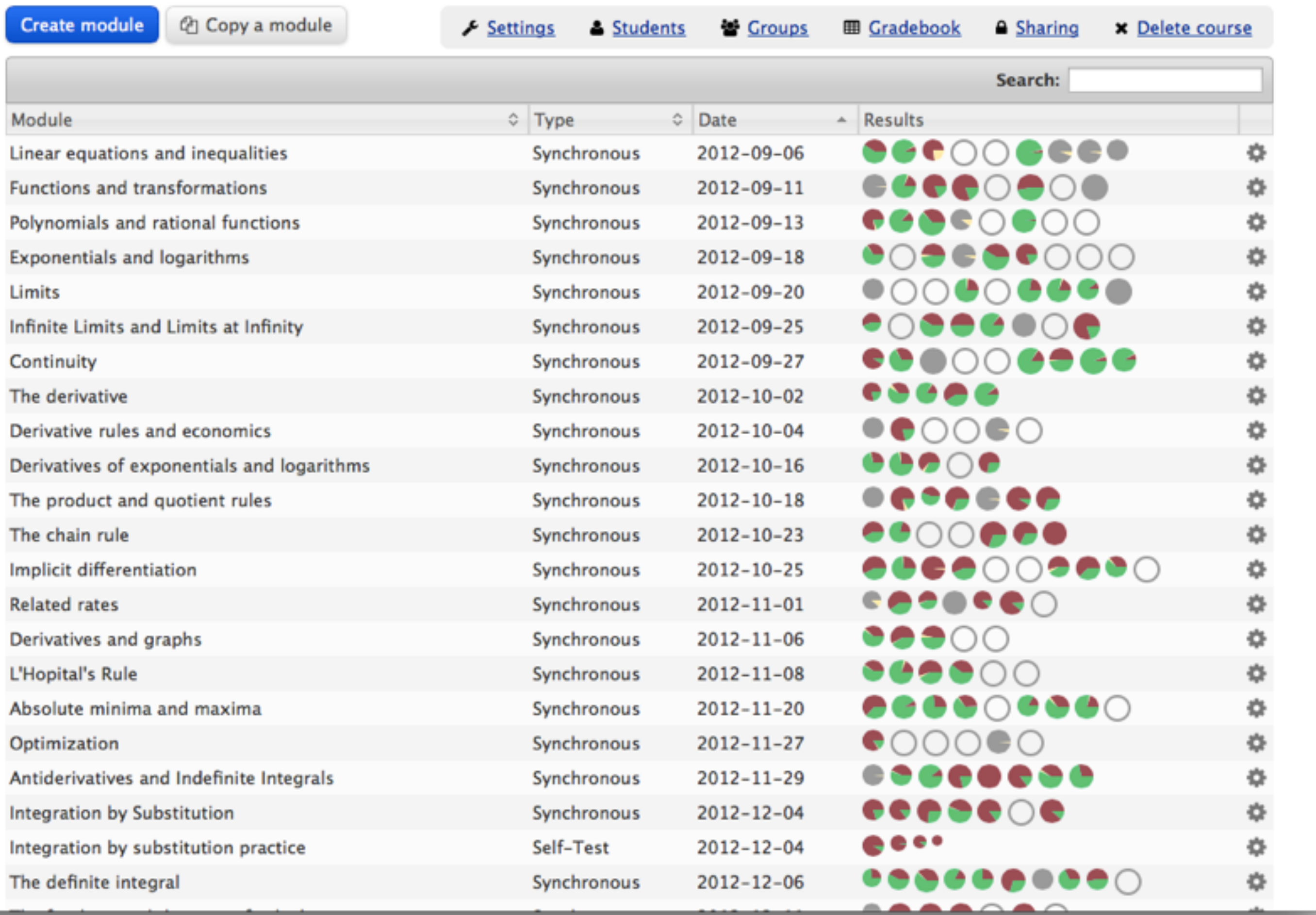




\section{learning|catalytics}

\section{My Courses > MA 121}

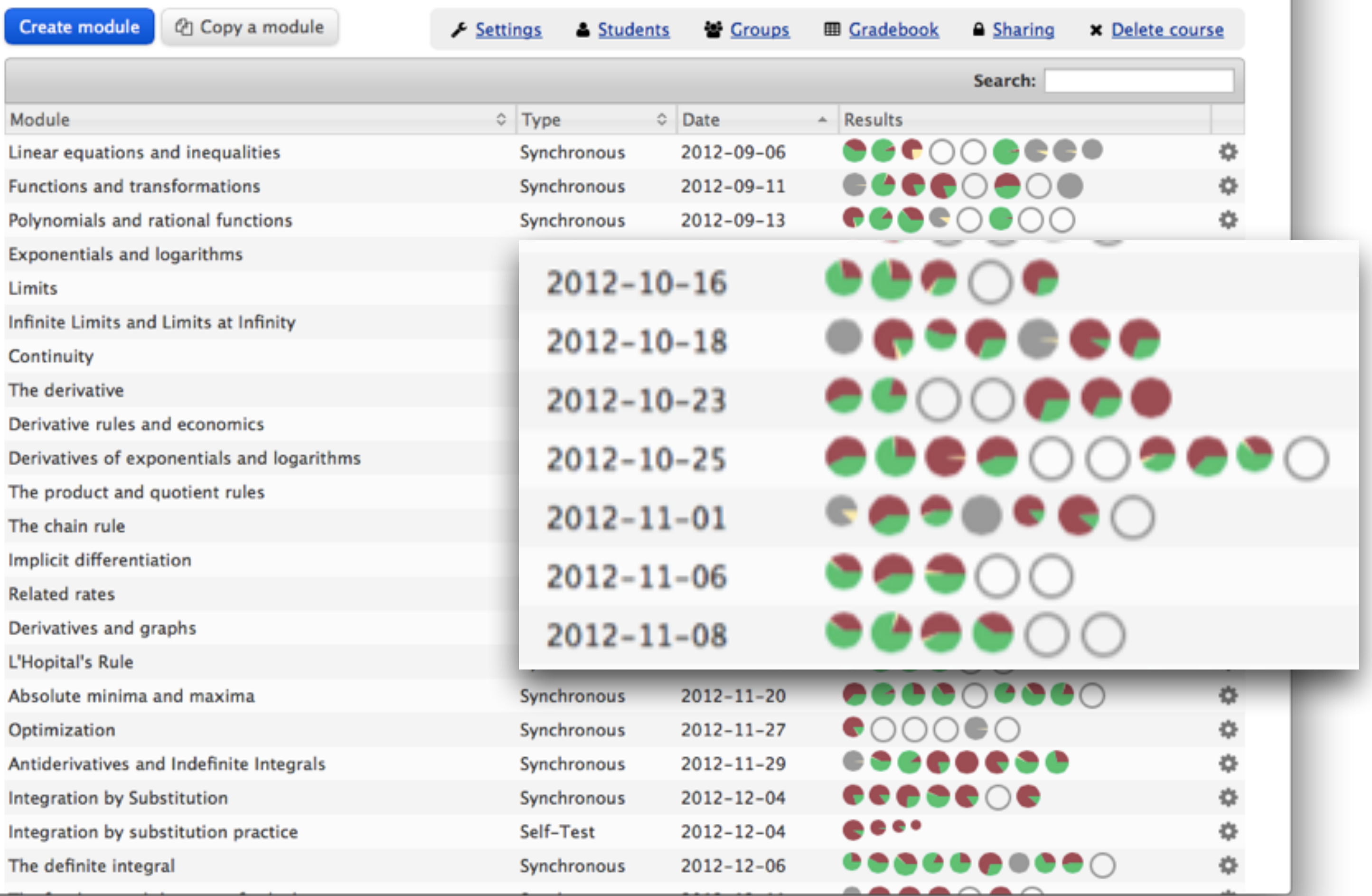




\section{ASYNCHRONOUS USE, TOO}

- Self-paced assessments (e.g., quizzes, homework, JiTT)

- Self-test, with instant feedback

- Team-based assessment

- Automated synchronous (for online courses) 
"Education is what remains after one has forgotten what one has learned in school."

- ALBERT EINSTEIN

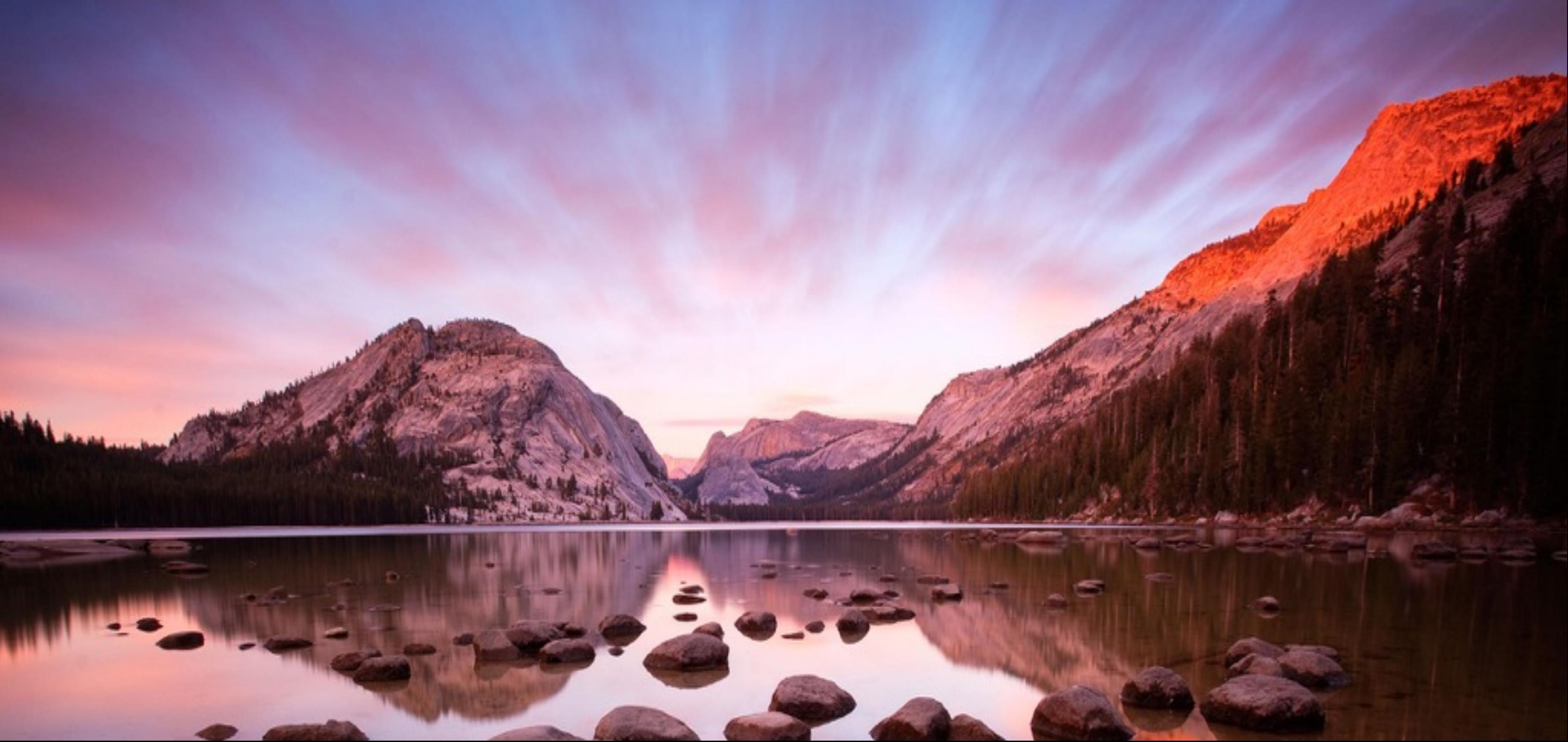


@BRIANLUKOFF

BRIAN.LUKOFF@GMAIL.COM

THANK YOU! 